\title{
3D Electron Microscopy Study of Synaptic Organization of the Normal Human Transentorhinal Cortex and Its Possible Alterations in Alzheimer's Disease
}

\author{
M. Domínguez-Álvaro, ${ }^{1}$ M. Montero-Crespo, ${ }^{1,2}$ L. Blazquez-Llorca,, ${ }^{1,3}$ J. DeFelipe, ${ }^{1,2,4}$ and ${ }^{(0 L}$. \\ Alonso-Nanclares ${ }^{1,2,4}$
}

https://doi.org/10.1523/ENEURO.0140-19.2019

${ }^{1}$ Laboratorio Cajal de Circuitos Corticales, Centro de Tecnología Biomédica, Universidad Politécnica de Madrid, Madrid 28223, Spain, ${ }^{2}$ Instituto Cajal, Consejo Superior de Investigaciones Científicas (CSIC), Madrid 28002, Spain, ${ }^{3}$ Departamento de Psicobiología, Facultad de Psicología, Universidad Nacional de Educación a Distancia (UNED), Madrid 28040, Spain, and ${ }^{4}$ Centro de Investigación Biomédica en Red sobre Enfermedades Neurodegenerativas (CIBERNED), Madrid 28031, Spain

\begin{abstract}
The transentorhinal cortex (TEC) is an obliquely oriented cortex located in the medial temporal lobe and, together with the entorhinal cortex, is one of the first affected areas in Alzheimer's disease (AD). One of the most widely accepted hypotheses is that synaptopathy (synaptic alterations and loss) represents the major structural correlate of the cognitive decline observed in $A D$. However, very few electron microscope (EM) studies are available; the most common method to estimate synaptic density indirectly is by counting, at the light microscopic level, immunoreactive puncta using synaptic markers. To investigate synaptic morphology and possible alterations related to $A D$, a detailed three-dimensional (3D) ultrastructural analysis using focused ion beam/scanning EM (FIB/SEM) was performed in the neuropil of Layer II of the TEC in human brain samples from non-demented subjects and AD patients. Evaluation of the proportion and shape of asymmetric synapses (AS) and symmetric synapses (SS) targeting spines or dendritic shafts was performed using 3D reconstructions of every synapse. The 3D analysis of 4722 synapses revealed that the preferable targets were spine heads for AS and dendritic shafts for SS, both in control and $A D$ cases. However, in $A D$ patients, we observed a reduction in the percentage of synapses targeting spine heads. Regarding the shape of synapses, in both control cases and AD samples, the vast majority of synapses had a macular shape, followed by perforated or horseshoe-shaped synapses, with fragmented synapses being the least frequent type. Moreover, comparisons showed an increased number of fragmented AS in AD patients.
\end{abstract}

Key words: dementia; dendritic shafts; dendritic spines; FIB/SEM; synaptic morphology

\section{Significance Statement}

Determination of postsynaptic targets, shape and size of the synaptic junctions provide critical data on synaptic functionality. However, as far as we know, detailed three-dimensional (3D) synaptic morphology and identification of postsynaptic targets in serial sections have not been performed before in the human brain. The present study represents the first attempt to unveil the synaptic organization of the neuropil of the human brain at the ultrastructural level using 3D electron microscopy (EM). Our present results provide a new, large, quantitative ultrastructure dataset of the synaptic organization of the normal human cortex and of the synaptic alterations that occur in Alzheimer's disease (AD). Thus, these results may help to understand the relationship between alterations of the synaptic circuits and the cognitive deterioration in AD. 


\section{Introduction}

The transentorhinal cortex (TEC) is an obliquely oriented cortex located in the medial temporal lobe between the perirhinal cortex and the entorhinal cortex and is considered as a transitional zone between the periallocortex and the proisocortex (Braak and Braak, 1985; Braak et al., 1996; Insausti et al., 2017). This cortical region, together with the entorhinal cortex, is one of the first affected regions in Alzheimer's disease (AD). AD is characterized by two hallmark lesions: extracellular amyloid- $\beta$ $(\mathrm{A} \beta)$-plaques and intracellular neurofibrillary tangles of filamentous aggregates of hyperphosphorylated tau protein (Alzheimer's Association, 2018). In particular, neurofibrillary tangles first affect the TEC (Braak and Braak, 1991).

$\mathrm{A} \beta$ peptides and tau proteins play normal roles at the synapse, but under pathologic conditions, they may lead to toxic effects at both presynaptic and postsynaptic elements, leading to synaptic loss and causing dysfunction in neurotransmitter release (Spires-Jones and Hyman, 2014; Dorostkar et al., 2015; Henstridge et al., 2016; Rajmohan and Reddy, 2017; Zhou et al., 2017). At present, one of the most widely accepted hypothesis is that synaptopathy (synaptic alterations and loss) represents the major structural correlate of the cognitive decline observed in AD (Dickson et al., 1995; Sze et al., 1997; Masliah et al., 2001; Selkoe, 2002; Coleman et al., 2004; Arendt, 2009).

In a previous study, Domínguez-Álvaro et al. (2018) focused ion beam/scanning electron microscopy (FIB/ SEM) was used to study the possible alterations of synapses in the neuropil of Layer II of TEC in human brain samples from AD patients. Unexpectedly, it was observed that there were no significant differences in the density, size and spatial distribution of synapses between $A D$ and control samples. However, cortical thickness of the TEC in $A D$ patients was reduced $(35 \%$ thinner than in control subjects). Thus, a decrease in the total number of synapses in AD occurs in Layer II of the TEC. It was proposed

Received April 11, 2019; accepted May 27, 2019; First published June 19, 2019.

The authors declare no competing financial interests.

Author contributions: M.D.-A., M.M.-C., L.B.-L., and L.A.-N. performed research; M.D.-A. analyzed data; M.D.-A. and L.A.-N. wrote the paper; J.D. and L.A.-N. designed research.

This work was funded by grants from the "Ministerio de Ciencia, Innovación y Universidades" (grant PGC2018-094307-B-I00), Centro de Investigación Biomédica en Red sobre Enfermedades Neurodegenerativas (CIBERNED, Spain, CB06/05/0066), the Alzheimer's Association (ZEN-15-321663), and the European Union's Horizon 2020 Research and Innovation Program under grant agreement No. 785907 (Human Brain Project, second specific grant agreement [SGA2]). M.M.-C. was awarded an FPU contract (14/02245) from the Spanish "Ministerio de Educación, Cultura y Deporte" (MECD).

Acknowledgements: We thank Carmen Álvarez, Miriam Marín, and Lorena Valdés for their technical assistance; Dr. Bojan Mihaljevic for statistical assessment; Dr. Andrea Santuy for her patience; and Nick Guthrie for his excellent text editing.

Correspondence should be addressed to L. Alonso-Nanclares at aidil@cajal.csic.es.

https://doi.org/10.1523/ENEURO.0140-19.2019

Copyright (C) 2019 Domínguez-Álvaro et al.

This is an open-access article distributed under the terms of the Creative Commons Attribution 4.0 International license, which permits unrestricted use, distribution and reproduction in any medium provided that the original work is properly attributed. that the surviving TEC neurons might display a compensatory mechanism (such as the generation of new dendritic branches), which would explain the lack of changes in the synaptic density.

It is well established that synapses are continuously formed, eliminated and/or reshaped in response to synaptic activity (Fauth and Tetzlaff, 2016). Synapses are dynamic elements that can change in terms of not only their function, but also their morphology and molecular features (Wegner et al., 2018). These synaptic morphological changes may include an increase in the number of perforated synapses [with one or more holes in the postsynaptic density (PSD)] or fragmented synapses (with several PSDs; Geinisman et al., 1987, 1991, 1992a,b). How these morphological changes affect the synaptic function is unknown, but since larger PSDs contain more receptors, it may be that these changes are related to changes in the synaptic transmission efficiency, as proposed for long-term potentiation (LTP; Lüscher et al., 2000).

Changes in the postsynaptic elements have also been described in $A D$ patients and in animal models of $A D$, specifically, morphological alterations of dendritic spines (for simplicity, spines; Spires-Jones et al., 2007; Knafo et al., 2009; Tackenberg et al., 2009; Merino-Serrais et al., 2011, 2013; Pozueta et al., 2013), which are the major targets of excitatory synapses in the cerebral cortex (for review, see DeFelipe, 2015). Whether or not synaptic loss precedes neuronal loss by synaptic disconnection is not known, but previous studies on the morphological alterations in spines of pyramidal cells in AD patients (MerinoSerrais et al., 2013) appear to support the notion of synaptic loss preceding neuronal loss.

Finally, as far as we know, detailed three-dimensional (3D) synaptic morphology and identification of postsynaptic targets in serial sections have not been performed before in the human brain in either control cases or in $A D$ patients. Thus, in the present study, FIB/SEM was used to determine the proportion and shape of asymmetric synapses (AS) and symmetric synapses (SS) targeting spines or dendritic shafts of 4722 synapses that were 3D reconstructed from the neuropil of Layer II of the TEC, from AD patients and control (non-demented) subjects. Accordingly, the present study represents the first attempt to unveil the synaptic organization of the neuropil of the human brain in both control and AD. This study provides a new, large, quantitative ultrastructure dataset of the synaptic organization of the normal human cortex and of the possible synaptic alterations that occur in $A D$.

\section{Materials and Methods}

\section{Tissue preparation}

Human brain tissue was obtained at autopsy from three sources: Pathologic Anatomy Service of Bellvitge University Hospital (Barcelona, Spain); Centro Alzheimer Fundación Reina Sofía, CIEN Foundation (Madrid, Spain); and from the Unidad Asociada Neuromax, Laboratorio de Neuroanatomía Humana, Facultad de Medicina, Universidad de Castilla-La Mancha, Albacete and the Laboratorio 
Table 1. Clinical and neuropathological information

\begin{tabular}{|c|c|c|c|c|c|c|c|}
\hline Patient & Gender & $\begin{array}{c}\text { Age } \\
\text { (years) }\end{array}$ & $\begin{array}{l}\text { Cause } \\
\text { of death }\end{array}$ & $\begin{array}{l}\text { Postmortem } \\
\text { delay (h) }\end{array}$ & $\begin{array}{l}\text { Braak } \\
\text { stage }\end{array}$ & $\begin{array}{l}\text { CERAD } \\
\text { stage }\end{array}$ & $\begin{array}{c}\text { Neuropsychological } \\
\text { diagnosis }\end{array}$ \\
\hline$A B 1$ & Male & 45 & Lung cancer & $<1$ & NA & NA & NA \\
\hline AB2 & Female & 53 & Pulmonary shock & 4 & NA & NA & NA \\
\hline IF10 & Male & 66 & Bronchopneumonia plus cardiac failure & 2 & NA & NA & NA \\
\hline M16 & Male & 40 & Traffic accident & 3 & NA & NA & NA \\
\hline M17 & Male & 36 & Bronchopneumonia & 2.5 & NA & NA & NA \\
\hline IF1 & Female & 80 & - & 2 & IV & $\mathrm{B}$ & $\begin{array}{l}\text { No evidence of cognitive } \\
\text { impairment and dementia }\end{array}$ \\
\hline IF2 & Female & 94 & Pulmonary tuberculosis & 1.5 & $\mathrm{~V}$ & C & Dementia \\
\hline IF6 & Male & 85 & Pneumonia & 2 & III & $A$ & Mild cognitive impairment \\
\hline VK11 & Female & 87 & Respiratory inflammation & 1.5 & III-IV & $A$ & Dementia \\
\hline VK22 & Female & 86 & - & 2 & V & C & Dementia \\
\hline
\end{tabular}

Braak Stages (Braak and Braak, 1991): III (NFTs in entorhinal cortex and closely related areas); III-IV (NFTs abundant in amygdala and hippocampus. Extending slightly into association cortex); V-VI (NFTs widely distributed throughout the neocortex and ultimately involving primary motor and sensory areas). CERAD Stages (Mirra et al., 1991): A (Low density of neuritic plaques); B (Intermediate density of neuritic plaques); C (High density of neuritic plaques). NA: Not applicable; NFTs: neurofibrillary tangles. - : Not available.

Cajal de Circuitos Corticales UPM-CSIC (Madrid, Spain). The tissue was obtained following national laws and international ethical and technical guidelines on the use of human samples for biomedical research purposes. Briefly, tissue samples were obtained from five control cases (with no recorded neurological or psychiatric alterations) and five AD patients according to the neuropathological criteria provided by the above-mentioned centers. As outlined in a previous study, immunostaining for antiPHF- $_{\text {Tau }}$ and anti-A $\beta$ in the same control cases revealed no presence of $A \beta$-plaques and only occasional PHF-Tau neurons. By contrast, in AD patients, the same immunostaining revealed the presence of a variable number of immunoreactive PHF-Tau neurons and $\mathrm{A} \beta$-plaques (Domínguez-Álvaro et al., 2018, their Table 1).

In all cases, the time between death and tissue processing was lower than $4 \mathrm{~h}$ (Table 1). On removal, brain tissue was fixed in cold $4 \%$ paraformaldehyde (SigmaAldrich) in $0.1 \mathrm{M}$ sodium phosphate buffer (PB; Panreac, 131965), $\mathrm{pH} 7.4$, for 24-48 h. After fixation, the tissue was washed in $\mathrm{PB}$ and coronally sectioned in a vibratome (150- $\mu \mathrm{m}$ thickness; Vibratome Sectioning System, VT1200S Vibratome, Leica Biosystems). Sections containing TEC were selected and processed for EM as described elsewhere (Domínguez-Álvaro et al., 2018). Briefly, fixed sections were treated with $1 \% \mathrm{OsO}_{4}$ (Sigma, O5500), 0.1\% potassium ferrocyanide (Probus, 23345) and 0.003\% $\mathrm{CaCl}_{2}$ in sodium cacodylate buffer $(0.1 \mathrm{M})$ for $1 \mathrm{~h}$ at room temperature. After washing in PB, sections were stained with $2 \%$ uranyl acetate (EMS, 8473), and then dehydrated and flat-embedded in Araldite (TAAB, E021; DeFelipe and Fairén, 1993). Embedded sections were glued onto a blank Araldite block and trimmed. Semithin sections (1-2 $\mu \mathrm{m}$ thick) were obtained from the surface of the block and stained with $1 \%$ toluidine blue (Merck, 115930) in 1\% sodium borate (Panreac, 141644). The last semithin section (which corresponds to the section immediately adjacent to the block surface) was examined under light microscope and photographed to accurately locate the neuropil regions to be examined. Tissue shrinkage due to EM processing was estimated by measuring the area before and after processing to correct the final values in both control and AD cases (Merchán-Pérez et al., 2009). The area after processing was divided by the area value measured before processing to obtain a shrinkage factor for any area measurement $\left(\mathrm{p}^{2}\right)$ of 0.933 .

\section{D EM}

3D samples of Layer II from the TEC were obtained from all cases using a dual beam microscope (Crossbeam Neon40 EsB, Carl Zeiss NTS GmbH). This instrument combines a high-resolution field-emission SEM column with a focused gallium ion beam (FIB), which permits removal of thin layers of material from the sample surface on a nanometer scale. As soon as one layer of material is removed by the FIB ( $20 \mathrm{~nm}$ thick), the exposed surface of the sample is imaged by the SEM, using the backscattered electron detector. The sequential automated use of FIB milling and SEM imaging allowed us to obtain long series of photographs of a 3D sample of selected regions (Merchán-Pérez et al., 2009). Image resolution in the $x y$ plane was $5 \mathrm{~nm} /$ pixel. Resolution in the z-axis (section thickness) was $20 \mathrm{~nm}$, and image size was $2048 \times 1536$ pixels. The number of sections per stack ranged from 149 to 472 , which corresponds to a corrected volume ranging from 260.2 to $824.4 \mu \mathrm{m}^{3}$ (mean: $471.3 \mu \mathrm{m}^{3}$ ). A total of 30 stacks of images of the neuropil from Layer II of the TEC were obtained (three stacks per case, for all 10 cases; total volume studied: $14,140 \mu \mathrm{m}^{3}$ ). These images from the neuropil were obtained avoiding the neuronal and glial somata, blood vessels and, in the case of $A D$ cases, also avoiding $A \beta$-plaques (plaque-free regions) to avoid the effect of alterations of synapses in the vicinity of $A \beta$-plaques, which has been described previously (Blazquez-Llorca et al., 2013).

\section{Synaptic 3D analysis}

Stacks of images obtained by the FIB/SEM were analyzed using EspINA software (EspINA Interactive Neuron Analyzer, 2.1.9; http://cajalbbp.cesvima.upm.es/espina/); $3 \mathrm{D}$ reconstructed synapses were classified as AS (excitatory) or SS (inhibitory) based on their prominent or thin 


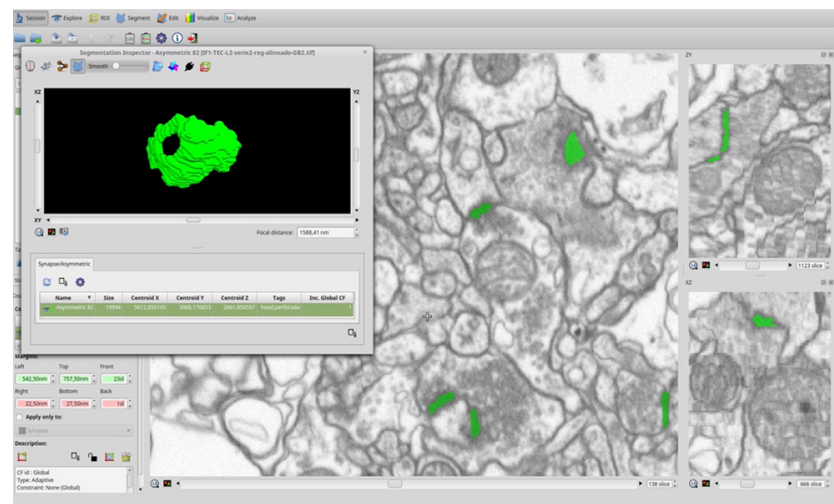

Movie 1. Video of the EspINA software user interface. FIB/SEM sections are viewed through the $x y$-plane (as obtained by FIB/ SEM microscopy) and $y z-$ and $x z$-plane. 3D reconstruction of a perforated synapse is shown in the three orthogonal planes. This $3 \mathrm{D}$ reconstruction of one perforated synapse is shown in green at the end of the video. The 3D reconstruction of the synapse allows us to identify the morphology of the synapse as perforated. [View online]

A

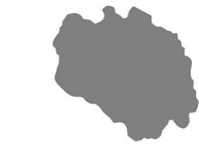

Macular

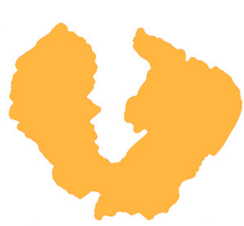

Horseshoe-shaped

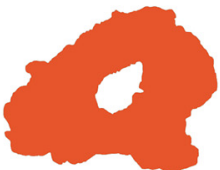

Perforated

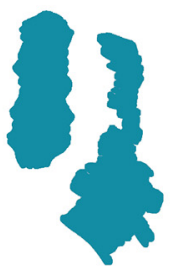

Fragmented
PSD, respectively (Gray, 1959; Colonnier, 1968; Peters and Palay, 1996).

EspINA software calculated the size of every synapse and also extracted the synaptic apposition surface (SAS) area, which provides the morphological features of the synapse, as an indicative measurement of the synaptic functionality (Morales et al., 2013).

EspINA was also used to visualize each of the reconstructed synapses in 3D and to detect the possible presence of perforations or deep indentations in their perimeters (an additional movie file shows this in more detail; Movie 1). Regarding the shape of the PSD, the synaptic junctions could be classified into four main types, according to Santuy et al. (2018a): macular (diskshaped PSD); perforated (with one or more holes in the PSD); horseshoe-shaped (perimeter with an indentation) and fragmented (irregular small disk-shaped PSDs with no connection between them; Fig. 1A).

To identify the postsynaptic targets of $3 \mathrm{D}$ reconstructed synapses, the image stack was navigated to determine whether the postsynaptic element was a dendritic spine or a dendritic shaft. A condition for unambiguous identi-

\section{B}

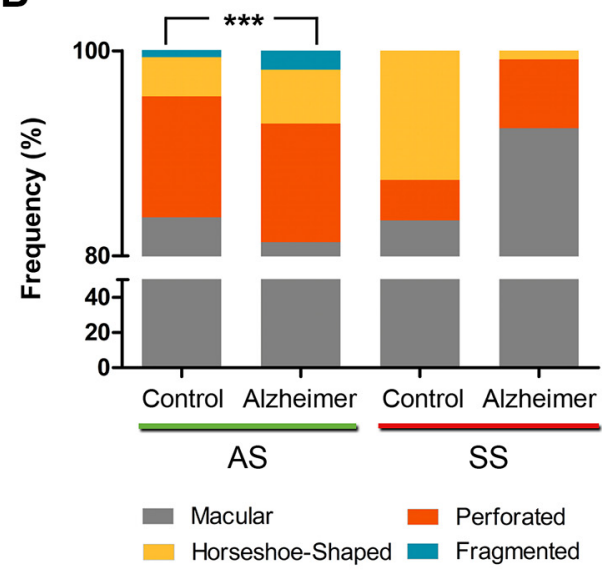

C

D
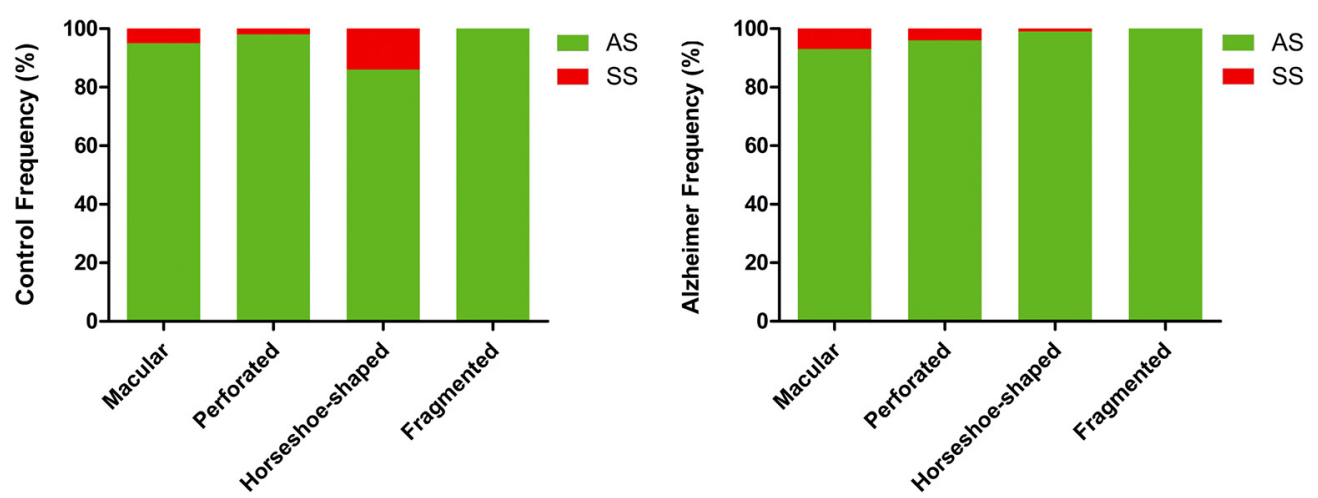

Figure 1. A, Schematic representation of the shape of the synaptic junctions: macular synapses with continuous disk-shaped PSD; perforated synapses with holes in the PSD; horseshoe-shaped with tortuous horseshoe-shaped perimeter with an indentation; and fragmented synapses with two PSDs with no connections between them. B. Proportion of macular, perforated, horseshoe-shaped, and segmented $A S$ and $S S$ in control cases and $A D$ patients. In AD patients, fragmented synapses were significantly more frequent than in control cases $\left(\chi^{2}, p<0.001\right)$. $\boldsymbol{C}$, Proportion of AS and SS belonging to each morphological category in control cases. The horseshoe-shaped synapses were significantly more frequent among SS than AS $\left(\chi^{2}, p<0.0001\right)$. D, Proportion of AS and SS belonging to each morphological category in AD cases. $* * * p<0.001$. 

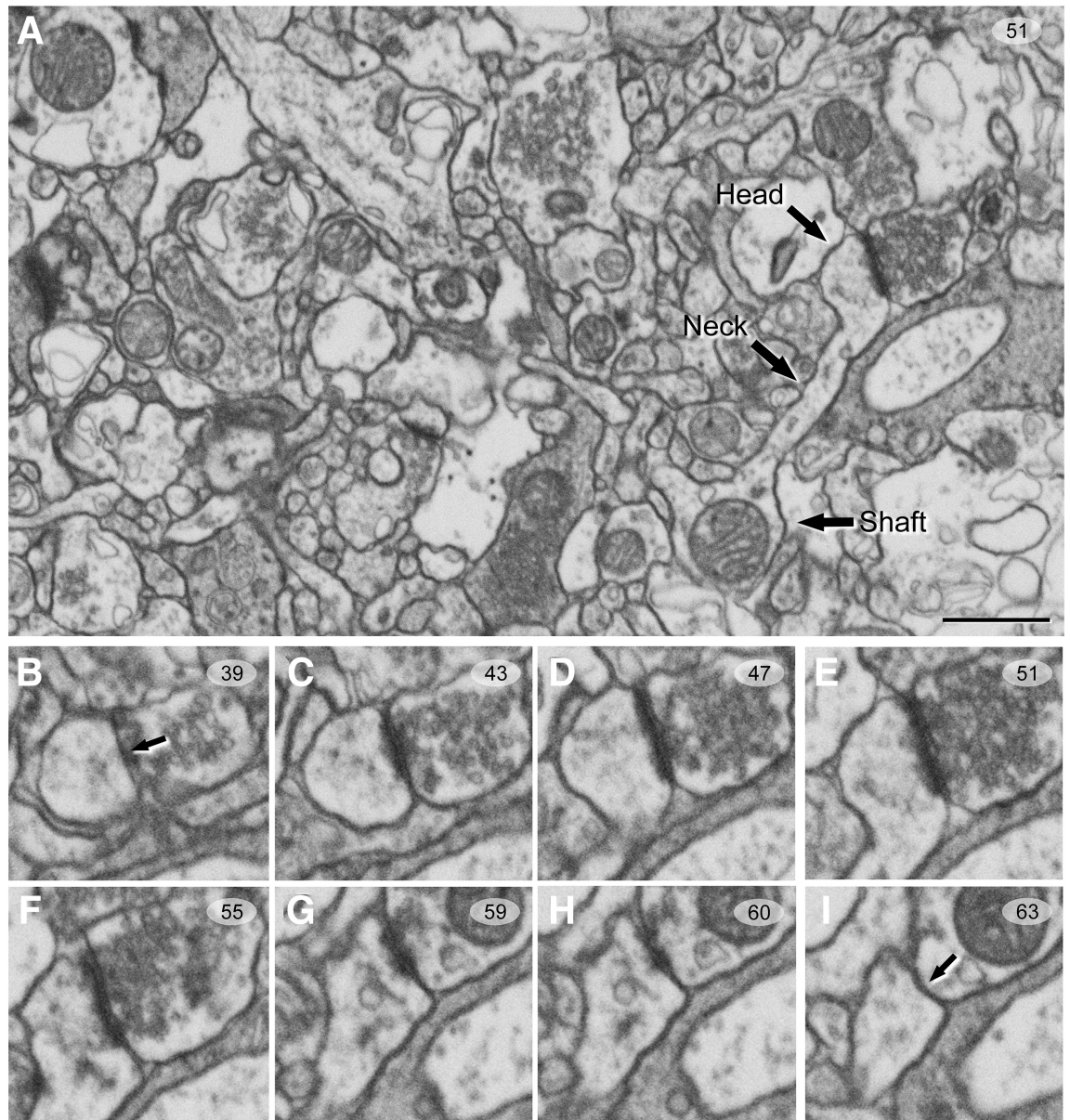

Figure 2. Serial images obtained by FIB/SEM from the human neuropil of Layer II of TEC. $\boldsymbol{A}$, Low-magnification photograph showing a spine head, spine neck, and dendritic shaft in a single image. $\boldsymbol{B}-\boldsymbol{I}$, Selected sections (39-63) from an FIB/SEM stack of serial sections, to illustrate an AS targeting a spine head. Arrows (in $\boldsymbol{B}, \boldsymbol{I}$ ) indicate the beginning and the ending, respectively, of the synapse targeting a spine head. Scale bar, show in $\boldsymbol{A}$, indicates $850 \mathrm{~nm}$ in $\boldsymbol{A}$ and $500 \mathrm{~nm}$ in $\boldsymbol{B}-\boldsymbol{I}$.

fication of spines, versus dendritic shafts, was that the dendritic spine could be visually traced to the parent dendrite (Fig. 2). Accordingly, when the postsynaptic element of a synapse was close to the margins and it was truncated by the borders of the stack, the identity of the postsynaptic target could not be determined. Truncated elements that could not be conclusively identified were labeled as "unknown." Therefore, the targets of synapses were classified into two main categories: dendritic spines and dendritic shafts. When the postsynaptic target was a dendritic spine, we further recorded the position of the synapse on the head or neck. We also determined whether the target dendrite was a spiny dendrite or a non-spiny one (Santuy et al., 2018b).

In addition, EspINA allowed the application of an unbiased 3D counting frame (CF) to perform direct counting (for details, see Merchán-Pérez et al., 2009). This 3D unbiased $C F$ is a regular rectangular prism enclosed by three acceptance planes and three exclusion planes marking its boundaries (Fig. 3). All objects within the CF are counted, as are those intersecting any of the acceptance planes, while objects that are outside the CF, or intersecting any of the exclusion planes, are not counted.
In this study, we have determined the morphology and postsynaptic target of 4722 synapses inside the 3D CF of the neuropil of Layer II of the TEC, from AD patients and control (with no recorded neurological or psychiatric alterations) subjects.

\section{Statistical analysis}

To perform statistical comparisons of AS and SS proportions, $\chi^{2}$ test was used for contingency tables. The same method was used to study whether there were significant differences between groups in relation to the shape of the synaptic junctions and their postsynaptic target. Briefly, in all the $\chi^{2}$ statistical analyses, we firstly performed an "omnibus test" based on $2 \times 4$ contingency tables. To further investigate the specific cells driving the significance of the $\chi^{2}$ test, partitioning procedure was applied to create $2 \times 2$ contingency tables (Sharpe, 2015). To identify possible differences within a group regarding the synaptic size (SAS area, perimeter and ratio) related to the shape of the synapses and their postsynaptic target, a Kruskal-Wallis (KW) nonparametric test was performed (the normality and homoscedasticity criteria were not met). Differences in the synaptic size between groups were evaluated by using the unpaired Mann- 


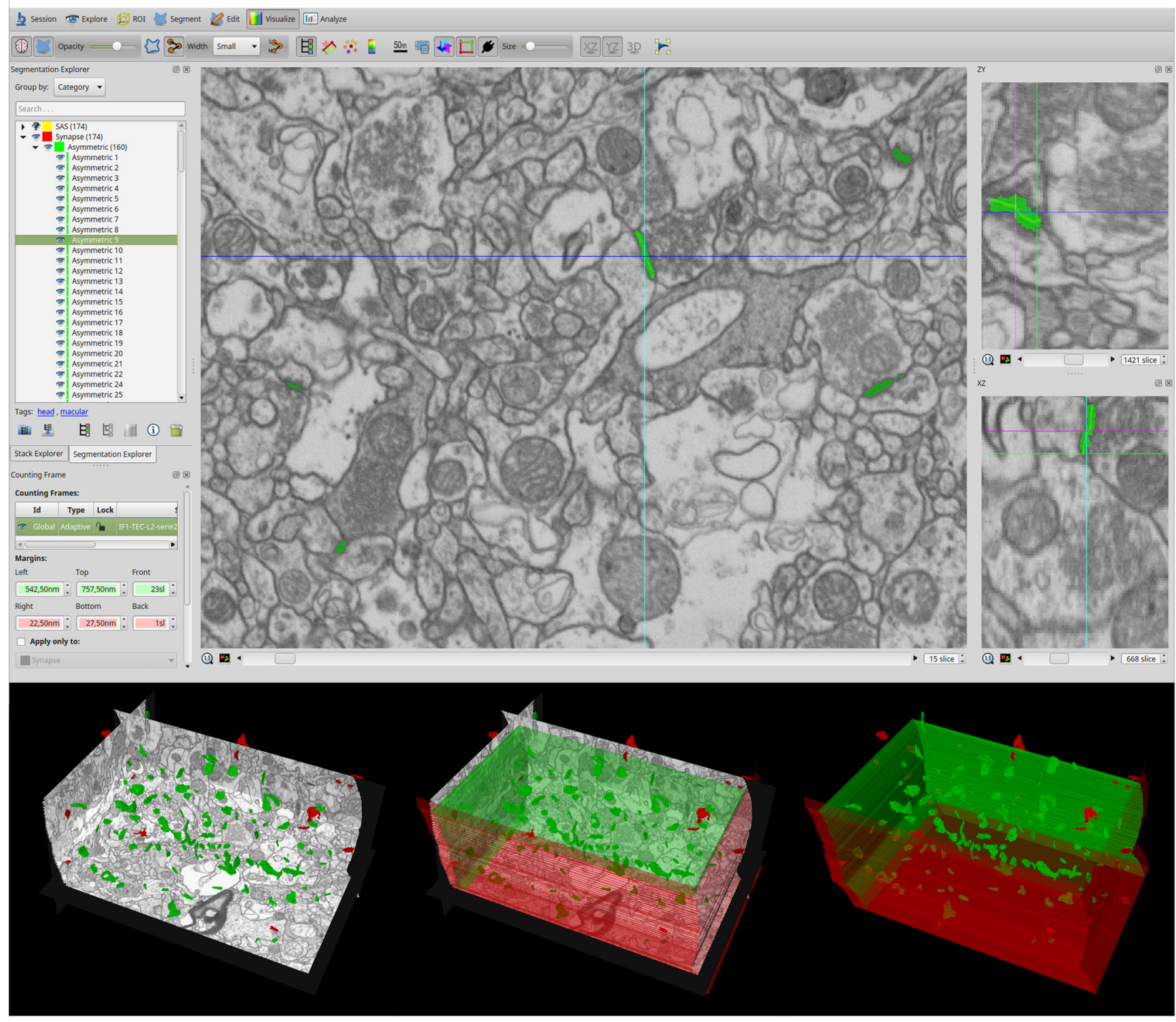

Figure 3. Screenshot of the EspINA software user interface. In the main window (top), the sections are viewed through the $x y$-plane (as obtained by FIB/SEM microscopy). The other two orthogonal planes, $y z$ and $x z$, are also shown in adjacent windows (on the right). The 3D windows (bottom left) show the three orthogonal planes and the 3D reconstruction of segmented synapses. A 3D rectangular unbiased CF is shown on the bottom. The three acceptance planes are represented in green and three exclusion planes in red. Synapses inside the CF are colored in green and synapses outside the CF in red.

Whitney (MW) nonparametric $U$ test. Frequency distribution analysis of the SAS was performed using Kolmogorov-Smirnov (KS) nonparametric test. Statistical studies were performed with the aid of the GraphPad Prism statistical package (Prism 5.00 for Windows, GraphPad Software Inc.) and SPSS program (IBM SPSS Statistics v24, IBM Corp.).

\section{Results}

Stacks of images obtained by the FIB/SEM were analyzed using EspINA software, which allows the segmentation of synapses in the reconstructed 3D volume (Morales et al., 2011). These TEC samples have been previously used to determine the density and size of synapses, as well as their spatial distribution (Domínguez-
Álvaro et al., 2018). Since the synaptic junctions were fully $3 \mathrm{D}$ reconstructed, as described elsewhere (MerchánPérez et al., 2009), each synapse could be classified as AS (excitatory) or SS (inhibitory), based on its prominent or thin PSD, respectively (Gray, 1959; Colonnier, 1968; Peters et al., 1991; Peters and Palay, 1996). In these stacks of images, it was also feasible to accurately determine the synaptic targets, which is critical from the point of view of the synaptic organization.

\section{Distribution of postsynaptic targets}

Postsynaptic targets were classified into two main categories: dendritic spines and dendritic shafts. In addition, when the postsynaptic target was a dendritic spine, we 
Table 2. Distribution of AS and SS on spines and dendritic shafts in control cases and AD patients

\begin{tabular}{|c|c|c|c|c|c|c|}
\hline Group & $\begin{array}{l}\text { Type of } \\
\text { synapse }\end{array}$ & $\begin{array}{c}\text { Synapses } \\
\text { on spine } \\
\text { heads }\end{array}$ & $\begin{array}{c}\text { Synapses } \\
\text { on spine } \\
\text { necks }\end{array}$ & $\begin{array}{c}\text { Synapses } \\
\text { on aspiny } \\
\text { dendritic } \\
\text { shaft }\end{array}$ & $\begin{array}{l}\text { Synapses } \\
\text { on spiny } \\
\text { dendritic } \\
\text { shaft }\end{array}$ & Total synapses \\
\hline \multirow[t]{2}{*}{ Control } & AS & $59.1 \%(825)$ & $0.5 \%(7)$ & $19.9 \%(278)$ & $20.5 \%(286)$ & $100 \%(1396)$ \\
\hline & SS & $7.1 \%(8)$ & $0.9 \%(1)$ & $38.4 \%(43)$ & $53.6 \%(60)$ & $100 \%(112)$ \\
\hline \multirow[t]{2}{*}{ Alzheimer } & AS & $50.2 \%(579)$ & $0.7 \%(8)$ & $28.0 \%$ (323) & $21.1 \%(243)$ & $100 \%(1153)$ \\
\hline & SS & $8.8 \%(9)$ & $1.0 \%(1)$ & $41.2 \%(42)$ & $49.0 \%(50)$ & $100 \%(102)$ \\
\hline
\end{tabular}

Synapses on spines have been sub-divided into those that are established on spine heads and those that are established on spine necks. Moreover, we differentiated between aspiny and spiny dendritic shafts. Data are expressed as percentages with the absolute number of synapses studied given in parentheses. Data for each individual case are represented in Table 2-1. Data expressed as absolute number of synapses were taken from this table to perform contingency tables showed in Table 2-2 and Table 2-3.

recorded the position of the synapse on the head or on the neck. When the postsynaptic target was a dendritic shaft, we also classified the dendrites as spiny or nonspiny, based on the presence or absence of spines, respectively.

\section{Control}

We determined the postsynaptic structures of 1396 AS whose target could be unambiguously identified as spines or dendritic shafts. Similarly, we analyzed a total of 112 SS.

In a previous study, it was found that AS outnumber SS 95:5 (Domínguez-Álvaro et al., 2018). In the present study, we observed that $59.1 \%$ of AS were established on spine heads and $0.5 \%$ on spine necks. The remaining AS were established on dendritic shafts: $40.4 \%$ (19.9\% on aspiny dendritic shafts and $20.5 \%$ on spiny shafts; Table 2; Extended Data Table 2-1). SS showed a clearly different preference for postsynaptic targets: 92\% were established on dendritic shafts $(53.6 \%$ on spiny dendritic shafts and $38.4 \%$ on aspiny shafts). That is, the majority of SS target dendritic shafts, and a small percentage of SS were established on spine heads $(7.1 \%)$ and spine necks (0.9\%; Table 2; Extended Data Table 2-1).

Therefore, we evaluated whether AS and SS had a preference for spines (heads and necks) or dendritic shafts. To evaluate this possibility, a $2 \times 4$ contingency table was created showing both types of synapses against the type of their postsynaptic target (Extended Data Table 2-2). The null hypothesis of this $\chi^{2}$ test was " $\mathrm{H}_{0}$ : type of synapse and type of postsynaptic target are independent"; $\chi^{2}$ test demonstrated that the null hypothesis must be rejected (Pearson- $\chi^{2}=117.06$; $\mathrm{df}=3 ; p<$ 0.0001 ), showing that there is an association between the type of synapses and the type of postsynaptic target. To determine which values in this test are driving this significance, $2 \times 2$ contingency tables were created (Extended Data Table 2-3). Since the observed values for SS in spine necks were $<5$, these data were discarded (Bewick et al., 2004). In the $2 \times 2$ tables, the expected counts of AS and SS on spine heads, aspiny dendritic shafts and spiny dendritic shafts were calculated from the marginal totals. In general, for any contingency table, the expected frequency for a cell in the ith row and the $j$ th column is $\mathrm{E}_{i j}=$ $\mathrm{T}_{i} \mathrm{~T}_{j} / \mathrm{T}$ where $\mathrm{T}_{i}$ is the marginal total for the $i$ th row, $\mathrm{T}_{j}$ is the marginal total for the jth column, and $\mathrm{T}$ is the total number of observations. $\chi^{2}$ tests were applied to these tables and the null hypothesis (" $\mathrm{H}_{0}$ : type of synapse and type of postsynaptic target are independent") was rejected; that is, there is an association between the type of synapse and the type of postsynaptic target. We found that AS had a significant preference for spine heads: $99.0 \%$ of AS and only $1.0 \%$ of SS were established on spine heads $\left(\chi^{2}, p<\right.$ $0.0001)$. By contrast, the SS showed a significant preference for dendritic shafts $\left(\chi^{2}, p<0.0001\right)$, both in aspiny dendritic shafts (receiving $86.6 \%$ AS and $13.4 \%$ SS) and spiny dendritic shafts (receiving $82.7 \%$ AS and $17.3 \%$ SS). Since the overall proportion of synapses on spines versus synapses on shafts was $\sim 56: 44$, each synaptic type, AS and SS, had a clear preference for a particular postsynaptic target.

When we differentiated the synapses according to their type (AS or SS) and their postsynaptic target (spine heads, spine necks or dendritic shafts), we found that $54.7 \%$ were AS targeting spine heads, $37.4 \%$ were AS on dendritic shafts, $6.8 \%$ corresponded to SS on dendritic shafts, and $0.5 \%$ were SS on spine heads (Fig. 4). However, few synapses targeted spine necks $(0.5 \%$ of AS and $0.1 \%$ of SS; Fig. 4).

We also determined the proportion of single or multiple synapses per spine head and found that the majority of synapses were single AS (94.5\%). The remaining 5.5\% were multiple synapses, which were found on the spine heads in different combinations as follows: $3.6 \%$ comprised two AS, with $1.9 \%$ comprising one AS and one SS (Fig. 5).

Furthermore, we examined the possible relationship between the postsynaptic target of the synapses and their synaptic size. This study was performed by examining the area, perimeter and curvature of the SAS from each AS and SS. In the case of the AS, the mean SAS curvature of synapses targeting spine heads was significantly higher than in synapses targeting dendritic shafts $(\mathrm{KW}, p<$ 0.001; Table 3; Fig. 6). In the case of SS, the number of synapses was considered too low to perform a robust statistical analysis.

$A D$

We examined the postsynaptic targets of 1153 AS and 102 SS that were unambiguously identified. The study of the preferred postsynaptic target revealed that $50.2 \%$ of AS were established on spine heads and $0.7 \%$ on spine necks. The remaining AS (49.1\%) were established on dendritic shafts: $28.0 \%$ on aspiny dendritic shafts and 

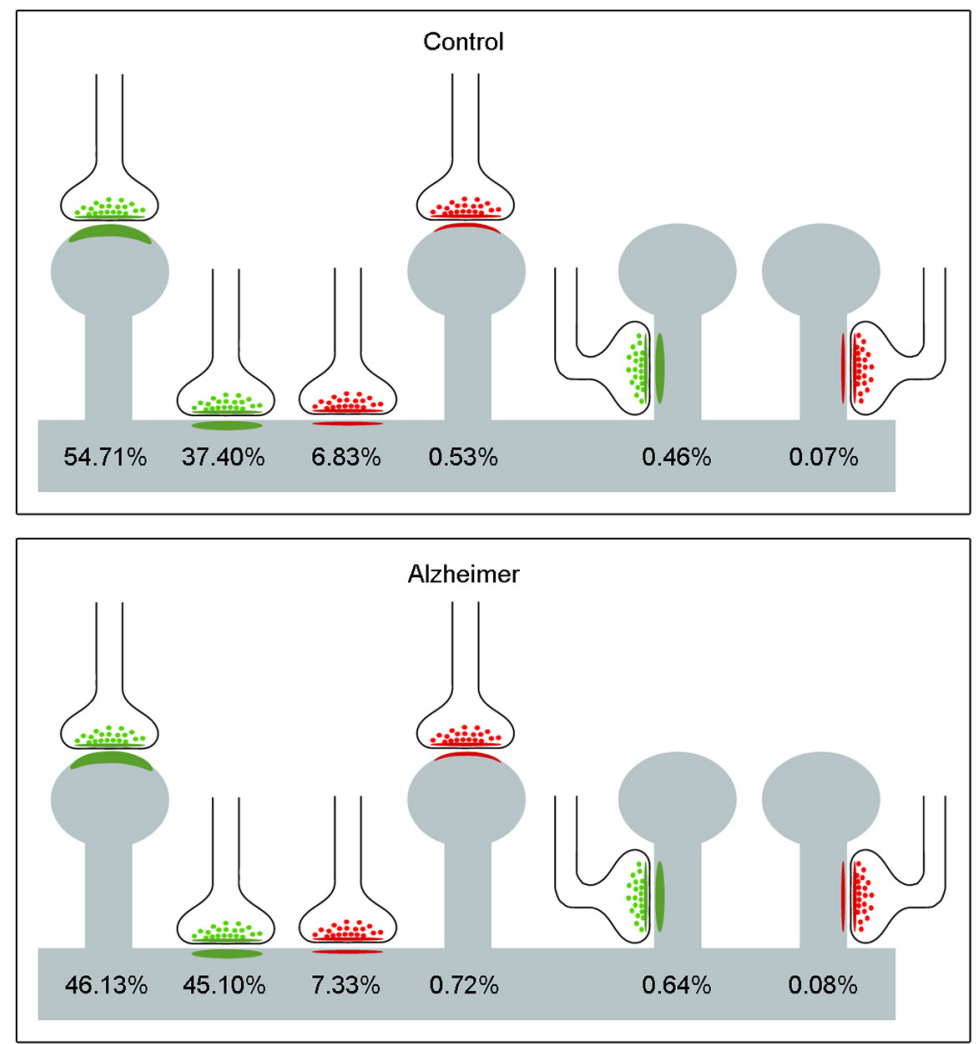

Figure 4. Representation of the distribution of AS (green) and SS (red) on spines and dendritic shafts. Percentages of each type are indicated. Synapses on spines have been sub-classified into those that are established on the head of the spine and those that are established on the neck. AS have been represented in green and SS in red. Control cases are represented on the top and AD patients on the bottom.

21.1\% on spiny shafts (Table 2; Extended Data Table 2-1). In these AD samples, SS also showed a clearly different preference pattern: $90.2 \%$ of SS targeted dendritic shafts (49.0\% on spiny dendritic shafts and $41.2 \%$ on aspiny shafts). A small percentage of SS were established on

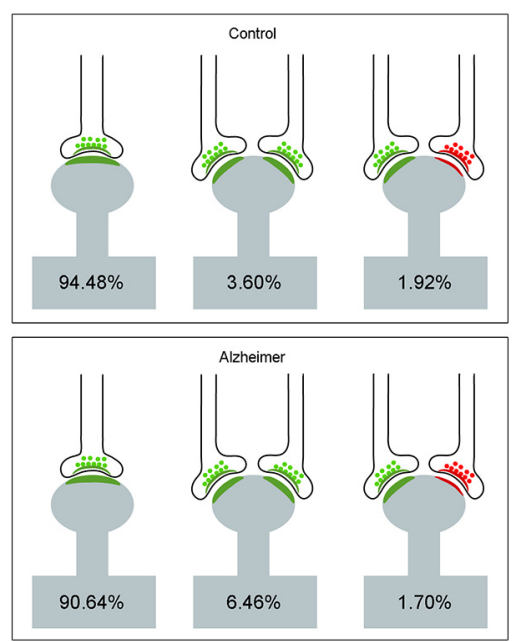

Figure 5. Schematic representation of single and multiple synapses on dendritic spine heads. Percentages of each type are indicated. Synapses on the necks and other combinations that were rarely found $(<1 \%)$ have not been represented. AS have been represented in green and SS in red. Control cases are represented on the top and $A D$ patients on the bottom. spine heads (8.8\%) and spine necks (1.0\%; Table 2; Extended Data Table 2-1).

To evaluate possible preference of AS and SS for spines or dendritic shafts in AD samples, the same analysis performed in control cases was used: $\chi^{2}$ test in $2 \times$ 4 and $2 \times 2$ contingency tables. We found that AS had a significant preference for spine heads: $98.5 \%$ of AS versus only $1.5 \%$ of SS $\left(\chi^{2}, p<0.0001\right)$. By contrast, the SS showed a significant preference for dendritic shafts $\left(\chi^{2}, p\right.$ $<0.0001$ ), with $82.9 \%$ of AS and $17.1 \%$ of SS on dendritic spiny shafts, and $88.5 \%$ of AS and $11.5 \%$ of SS on aspiny dendritic shafts.

Analysis of synapses according to their type (AS or SS) and their postsynaptic target (spine heads, spine necks and dendritic shafts) showed that, in AD samples, $46.1 \%$ of the synapses were AS targeting spine heads, $45.1 \%$ were AS on dendritic shafts, $7.3 \%$ corresponded to SS located on dendritic shafts and $0.7 \%$ to SS on spines (Fig. 4). Similar to observations with the control cases, there were few synapses targeting spine necks ( $0.7 \%$ for AS and $0.1 \%$ for SS; Fig. 4).

The presence of single or multiple synapses per spine head was also examined. The majority of synapses established on spine heads were single AS (90.6\%) and the least frequent type was single SS $(0.2 \%)$ on a spine head. The remaining $9.2 \%$ were multiple synapses, which were found on the spine heads in different combinations, as follows (Fig. 5): $6.5 \%$ comprised two AS, with $1.7 \%$ comprising one AS and one SS, and $1.0 \%$ comprising two AS and one SS (not shown). 
Table 3. Data regarding area $\left(\mathrm{nm}^{2}\right)$, perimeter $(\mathrm{nm})$, and curvature (ratio) of the SAS from synapses on spines and dendritic shafts in control cases and AD patients

\begin{tabular}{|c|c|c|c|c|c|}
\hline Group & $\begin{array}{l}\text { Postsynaptic } \\
\text { structure }\end{array}$ & $\begin{array}{l}\text { Type of } \\
\text { synapse }\end{array}$ & $\begin{array}{c}\text { Area of SAS } \\
\left(\mathrm{nm}^{2} ; \text { mean } \pm \text { SEM) }\right.\end{array}$ & $\begin{array}{c}\text { Perimeter of } \\
\text { SAS }(\mathrm{nm} ; \text { mean } \pm \text { SEM) }\end{array}$ & $\begin{array}{c}\text { Curvature of } \\
\text { SAS (mean } \pm \text { SEM) }\end{array}$ \\
\hline \multirow[t]{6}{*}{ Control } & Spine heads & AS & $14,5013 \pm 4103$ & $1877 \pm 38$ & $0.05 \pm 0.001$ \\
\hline & & SS & $81,295 \pm 12,011$ & $1380 \pm 138$ & $0.05 \pm 0.010$ \\
\hline & Spine necks & AS & $82,219 \pm 23,461$ & $1413 \pm 255$ & $0.04 \pm 0.004$ \\
\hline & & SS & $19,199 \pm 0$ & $627.7 \pm 0$ & $0.04 \pm 0$ \\
\hline & Dendritic shafts & AS & $115,703 \pm 2845$ & $1613 \pm 24$ & $0.04 \pm 0.001$ \\
\hline & & SS & $76,129 \pm 4299$ & $1442 \pm 51$ & $0.06 \pm 0.005$ \\
\hline \multirow[t]{6}{*}{ Alzheimer } & Spine heads & AS & $135,310 \pm 4762$ & $1815 \pm 47$ & $0.05 \pm 0.002$ \\
\hline & & SS & $50,292 \pm 12,137$ & $1014 \pm 128$ & $0.06 \pm 0.010$ \\
\hline & Spine necks & AS & $61,658 \pm 13,211$ & $1150 \pm 119$ & $0.05 \pm 0.005$ \\
\hline & & SS & $55,339 \pm 0$ & $1269 \pm 0$ & $0.11 \pm 0$ \\
\hline & Dendritic shafts & AS & $119,272 \pm 3335$ & $1638 \pm 32$ & $0.04 \pm 0.001$ \\
\hline & & SS & $78,687 \pm 5885$ & $1280 \pm 50$ & $0.06 \pm 0.005$ \\
\hline
\end{tabular}

All data are corrected for shrinkage factor. SEM: standard error of the mean.

In AD samples, we also evaluated whether the postsynaptic target was related to the size of the synaptic junctions. For this purpose, we examined the area, perimeter and curvature ratio of the SAS from each AS and SS. In the case of the AS, the mean SAS curvature ratio of synapses targeting spine heads was significantly higher than that found in synapses targeting dendritic shafts (KW, $p<0.001$; Table 3; Fig. 6). In the case of SS, the number of these synapses was not sufficient to perform a robust statistical analysis.
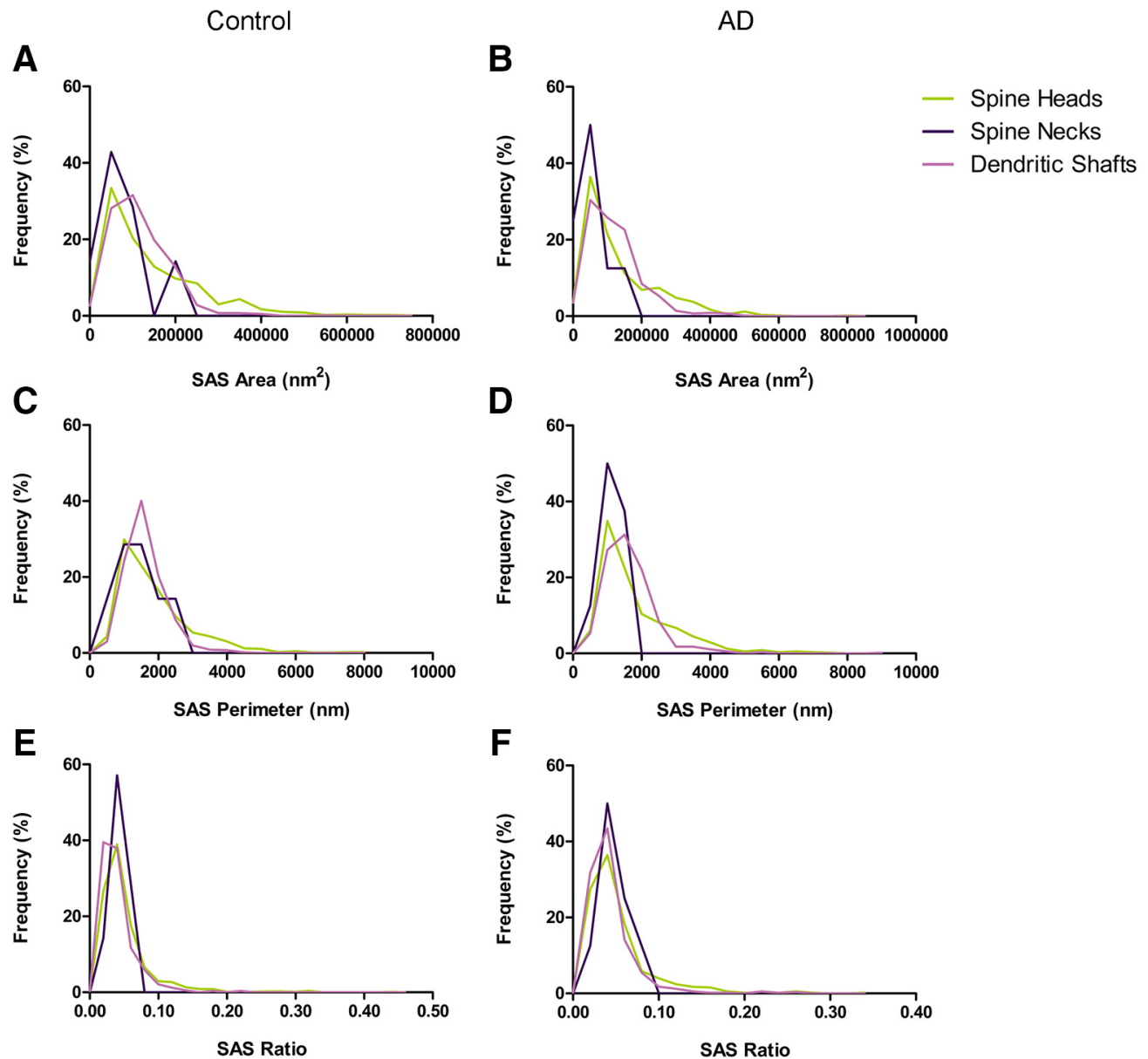

Figure 6. Frequency histograms of the SAS area $(\boldsymbol{A}, \boldsymbol{B})$, perimeter $(\boldsymbol{C}, \boldsymbol{D})$, and curvature $(\boldsymbol{E}, \boldsymbol{F})$ of $\mathrm{AS}$ targeting spine heads, spine necks, and dendritic shafts from control cases $(\boldsymbol{A}, \boldsymbol{C}, \boldsymbol{E})$ and from $A D$ patients $(\boldsymbol{B}, \boldsymbol{D}, \boldsymbol{F})$. The mean $S A S$ curvature ratio of synapses targeting spine heads was significantly higher than in synapses targeting dendritic shafts (KW, $p<0.0001)$, both in control cases and $A D$ patients. 

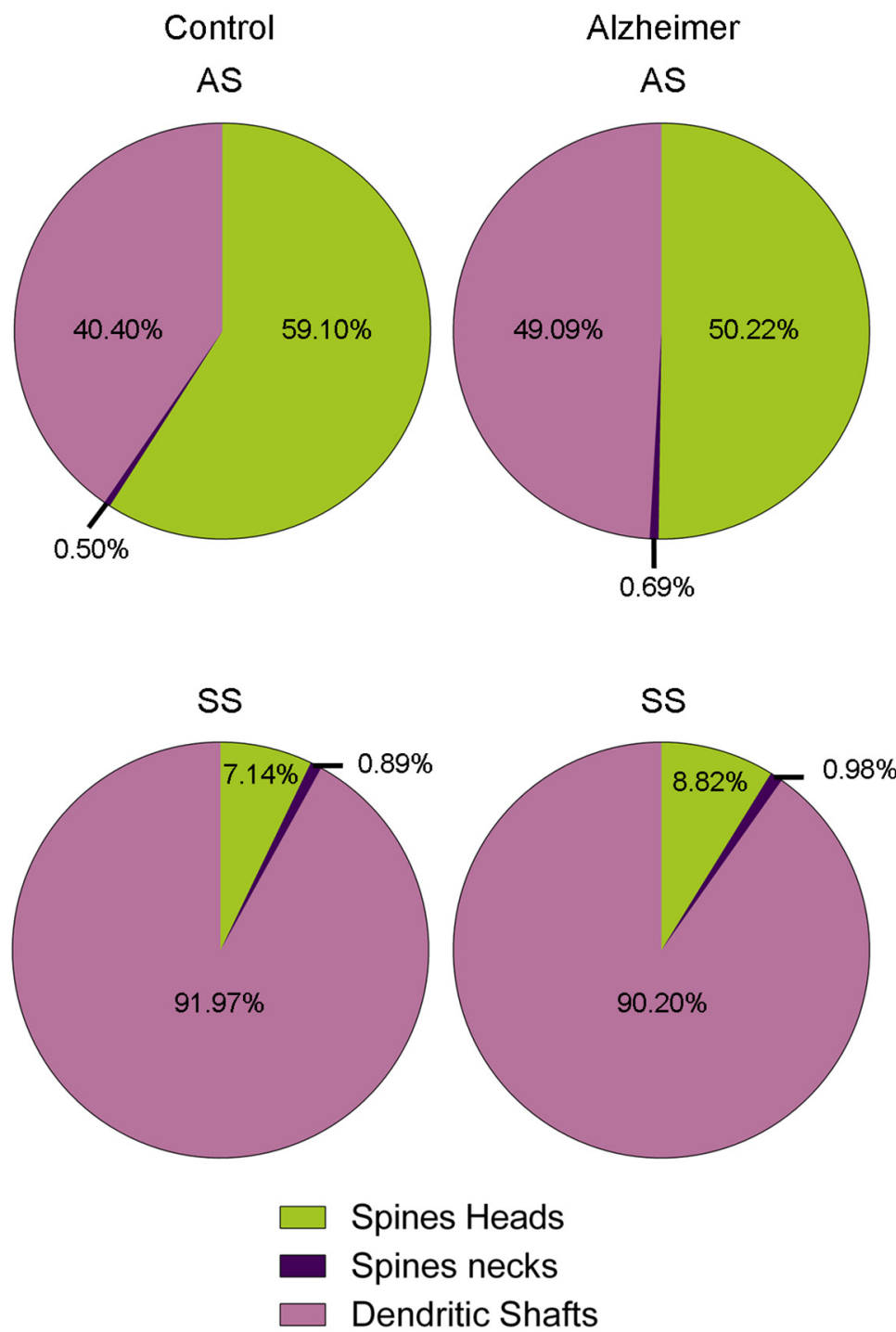

Figure 7. Proportion of AS and SS on spines and dendritic shafts in control and AD cases. In AD patients, there is a significantly lower number of AS targeting spine heads $\left(\chi^{2}, p<0.001\right)$ and a significantly higher number of AS targeting dendritic shafts $\left(\chi^{2}, p<0.001\right)$. Data from SS shows no apparent differences between groups.

The analysis of SAS features to compare between control and $A D$ samples showed no differences between groups (MW, $p>0.05$ ). Likewise, frequency distribution analysis of SAS did not reveal significant differences (KS, $p>0.01$; Fig. 6).

To evaluate possible differences in the postsynaptic targets in AD patients compared to control cases, $\chi^{2}$ tests in $2 \times 4$ and $2 \times 2$ contingency tables were performed. In this case, contingency tables considered both control and $A D$ samples against the type of postsynaptic target. For $A S$, in $A D$ patients there were significantly less synapses targeting spine heads compared to control cases $\left(\chi^{2}, p<\right.$ 0.001; Fig. 7). By contrast, we observed that significantly more synapses targeted dendritic shafts in AD patients $\left(\chi^{2}, p<0.001\right.$; Fig. 7). No differences were found regarding synapses targeting spine necks $\left(\chi^{2}, p=\right.$ 0.7099 ; Fig. 7). Concerning SS, the number of synapses examined was not sufficient to perform a robust statistical analysis.

\section{The shape and size of the synaptic junctions}

Regarding the synaptic shape, synapses were categorized into four main types according to Santuy et al. (2018a): macular, perforated, horseshoe-shaped, and fragmented synapses. Briefly, macular synapses presented continuous disk-shaped PSD; those with holes in the PSDs were classified as perforated synapses; synapses with tortuous horseshoe-shaped perimeters with an indentation were called "horseshoe-shaped"; and irregular small disk-shaped PSDs with no connection between them were considered as "fragmented" synapses (Fig. 1A).

\section{Control}

In control cases, 2561 AS were identified and fully reconstructed in 3D. The majority of these were macular (83.8\%), followed by perforated synapses (11.8\%). Relatively few were horseshoe-shaped (3.8\%), and much fewer still were fragmented synapses $(0.6 \%$; Table 4 ; 
Table 4. Proportion of the different shapes of synaptic junctions in control and AD patients

\begin{tabular}{|c|c|c|c|c|c|c|}
\hline Group & $\begin{array}{l}\text { Type of } \\
\text { synapse }\end{array}$ & $\begin{array}{l}\text { Macular } \\
\text { synapses }\end{array}$ & $\begin{array}{l}\text { Perforated } \\
\text { synapses }\end{array}$ & $\begin{array}{l}\text { Horseshoe-shaped } \\
\text { synapses }\end{array}$ & $\begin{array}{l}\text { Fragmented } \\
\text { synapses }\end{array}$ & $\begin{array}{c}\text { Total } \\
\text { synapses }\end{array}$ \\
\hline \multirow[t]{2}{*}{ Control } & AS & $83.8 \%(2145)$ & $11.8 \%(302)$ & $3.8 \%(98)$ & $0.6 \%(16)$ & $100 \%(2561)$ \\
\hline & SS & $83.5 \%(106)$ & $3.9 \%(5)$ & $12.6 \%(16)$ & $0.0 \%(0)$ & $100 \%$ (127) \\
\hline \multirow[t]{2}{*}{ Alzheimer } & AS & $81.4 \%(1558)$ & $11.5 \%(221)$ & $5.3 \%(101)$ & $1.8 \%(35)$ & $100 \%(1915)$ \\
\hline & SS & $92.5 \%(110)$ & $6.7 \%(8)$ & $0.8 \%(1)$ & $0.0 \%(0)$ & $100 \%(119)$ \\
\hline
\end{tabular}

Data are given as percentages with the absolute number of synapses studied in parentheses. Data for each individual case are represented in Table $4-1$.

Extended Data Table 4-1). Regarding SS, we identified and fully reconstructed in 3D a total of 127 synapses. The majority were macular-shaped (83.5\%), followed by horseshoe-shaped (12.6\%). The least frequent type was the perforated $(3.9 \%)$ and no fragmented SS were found (Table 4; Extended Data Table 4-1).

To evaluate possible association of AS and SS regarding the synaptic shape, again $\chi^{2}$ tests in $2 \times 4$ and $2 \times 2$ contingency tables were created, considering both types of synapses against the morphological synaptic type. The null hypotheses of these $\chi^{2}$ tests were " $\mathrm{H}_{0}$ : type of synapse and morphological synaptic type are independent." We found that $95.3 \%$ of macular synapses were AS and $4.7 \%$ were SS. This proportion was slightly different in perforated synapses (98.4\% AS and $1.6 \%$ SS), but in the case of horseshoe-shaped synapses, the proportion of AS was significantly lower $(86.0 \%$ were AS and $14 \%$ SS; $\chi^{2}, p<0.0001$ ), indicating that the horseshoe-shaped synapses were more frequent among SS than AS. Regarding the fragmented synapses, 100\% were AS (Fig. $1 C)$.

We also determined whether the shape of the synapses was associated with differences in their size. For this purpose, we examined the area, perimeter and curvature ratio of the SAS from each AS and SS. In the case of the AS, the mean SAS area, perimeter and curvature ratio of macular synapses were all significantly smaller than in perforated, horseshoe-shaped and fragmented synapses (KW, $p<0.0001$; Table 5; Fig. 8). Although we observed the same tendency in the case of SS (smaller macular synapses than perforated and horseshoe-shaped synapses), only five perforated synapses and 16 horseshoeshaped ones were found, and therefore, statistical analysis was not applied.

$A D$

In AD patients, a total of 1915 AS were identified and fully $3 \mathrm{D}$ reconstructed. The majority of these synapses were macular-shaped $(81.4 \%)$, followed by perforated synapses (11.5\%), horseshoe-shaped $(5.3 \%)$, and only $1.8 \%$ were fragmented synapses. Concerning SS, we identified and fully 3D reconstructed a total of 119 synapses. The majority were macular (92.5\%), followed by perforated $(6.7 \%)$. The least frequent type was the horseshoe-shaped $(0.8 \%)$, and similar to the observations with control cases, fragmented SS were not found in AD patients (Table 4; Extended Data Table 4-1).

As occurred in the control cases, we found that $93.4 \%$ of macular synapses were AS and $6.6 \%$ were SS. This proportion was slightly different in perforated synapses (96.5\% AS and 3.5\% SS) and horseshoe-shaped synapses $(99.0 \%$ AS and $1.0 \%$ SS). Regarding the fragmented synapses, $100 \%$ were AS (Fig. 1D).

Table 5. Data regarding area $\left(\mathrm{nm}^{2}\right)$, perimeter $(\mathrm{nm})$, and curvature (ratio) of the SAS of macular, perforated, horseshoeshaped, and fragmented synapses in control cases and AD patients

\begin{tabular}{|c|c|c|c|c|c|}
\hline Group & $\begin{array}{l}\text { Shape of } \\
\text { synapses }\end{array}$ & Type of synapse & $\begin{array}{c}\text { Area of SAS } \\
\left(\mathrm{nm}^{2} ; \text { mean } \pm \text { SEM) }\right.\end{array}$ & $\begin{array}{c}\text { Perimeter of } \\
\text { SAS (nm; mean } \pm \text { SEM) }\end{array}$ & $\begin{array}{c}\text { Curvature of } \\
\text { SAS (mean } \pm \text { SEM) }\end{array}$ \\
\hline \multirow[t]{8}{*}{ Control } & Macular & AS & $88,272 \pm 1283$ & $1352 \pm 11$ & $0.04 \pm 0.001$ \\
\hline & & SS & $70,960 \pm 3764$ & $1306 \pm 40$ & $0.05 \pm 0.005$ \\
\hline & Perforated & AS & $264,960 \pm 6606$ & $2914 \pm 58$ & $0.07 \pm 0.003$ \\
\hline & & SS & $108,320 \pm 22,066$ & $2080 \pm 279$ & $0.07 \pm 0.016$ \\
\hline & Horseshoe-shaped & AS & $262,251 \pm 13,757$ & $3725 \pm 163$ & $0.09 \pm 0.007$ \\
\hline & & SS & $88,466 \pm 13204$ & $1876 \pm 153$ & $0.06 \pm 0.011$ \\
\hline & Fragmented & AS & $360,245 \pm 34,068$ & $3735 \pm 435$ & $0.14 \pm 0.025$ \\
\hline & & SS & - & - & - \\
\hline \multirow[t]{8}{*}{ Alzheimer } & Macular & AS & $91,162 \pm 1689$ & $1367 \pm 14$ & $0.04 \pm 0.001$ \\
\hline & & SS & $59,436 \pm 3156$ & $1224 \pm 42$ & $0.06 \pm 0.005$ \\
\hline & Perforated & AS & $259,540 \pm 7942$ & $2879 \pm 73$ & $0.07 \pm 0.003$ \\
\hline & & SS & $123,147 \pm 14,857$ & $1776 \pm 129$ & $0.03 \pm 0.006$ \\
\hline & Horseshoe-shaped & AS & $237,778 \pm 9524$ & $3568 \pm 127$ & $0.08 \pm 0.006$ \\
\hline & & SS & $115,312 \pm 0.0$ & $2431 \pm 0$ & $0.07 \pm 0.000$ \\
\hline & Fragmented & AS & $303,922 \pm 21,783$ & $2985 \pm 210$ & $0.13 \pm 0.014$ \\
\hline & & SS & - & - & - \\
\hline
\end{tabular}

All data are corrected for shrinkage factor. SEM: standard error of the mean. 
Control

A

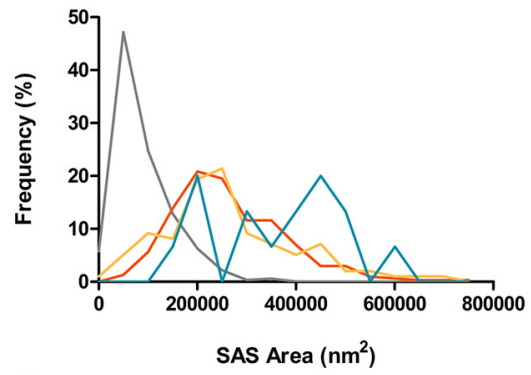

C

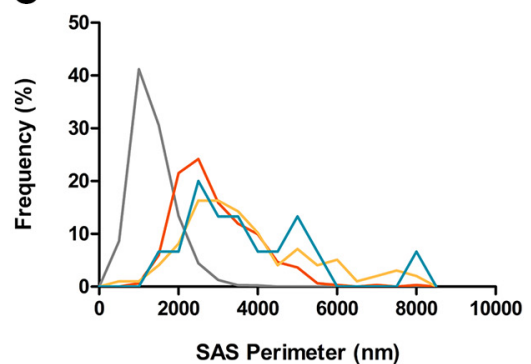

E

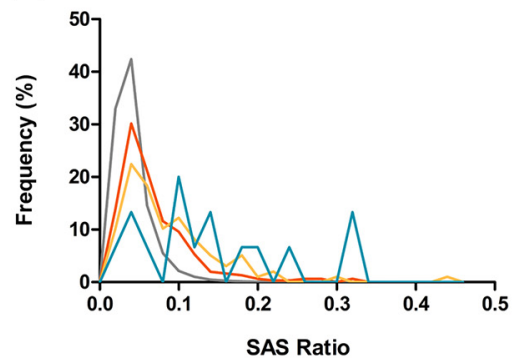

$A D$

B

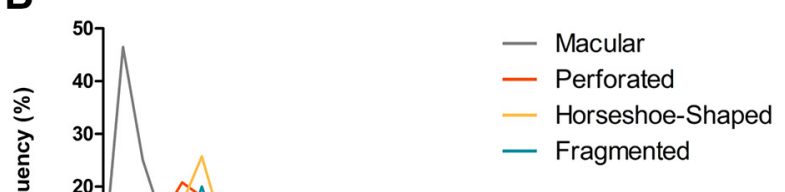

D

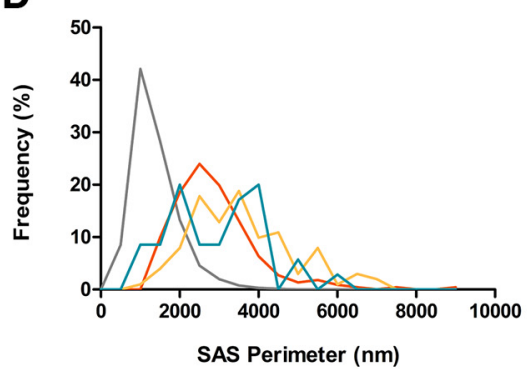

F

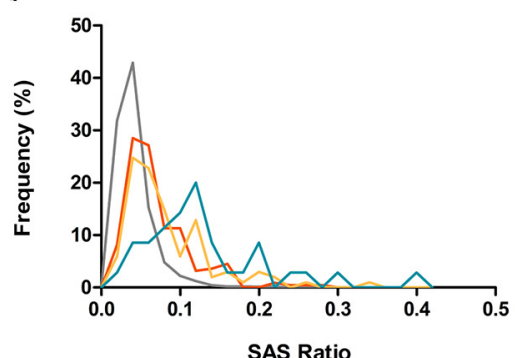

Figure 8. Frequency histograms of the SAS area $(\boldsymbol{A}, \boldsymbol{B})$, perimeter $(\boldsymbol{C}, \boldsymbol{D})$, and curvature $(\boldsymbol{E}, \boldsymbol{F})$ of macular, perforated, horseshoeshaped and segmented AS from control cases $(\boldsymbol{A}, \boldsymbol{C}, \boldsymbol{E})$ and from AD patients $(\boldsymbol{B}, \boldsymbol{D}, \boldsymbol{F})$. The mean SAS area, perimeter and curvature of macular synapses was significantly smaller than in perforated, horseshoe-shaped and segmented synapses (KW, $p<0.0001)$, both in control cases and AD patients.

To evaluate possible differences in the proportion of the synaptic shapes between control cases and AD patients, $\chi^{2}$ tests in $2 \times 4$ and $2 \times 2$ contingency tables were performed. In this case, contingency tables considered both control and $A D$ samples against the morphological synaptic type. For AS the results indicated that, in AD patients, fragmented synapses were more frequent than in control cases $\left(\chi^{2}, p<0.001\right)$. This difference was not significant regarding macular, perforated and horseshoe synapses $\left(\chi^{2}, p>0.01\right.$; Fig. $\left.1 B\right)$, but we observed a slightly higher number in horseshoe synapses $\left(\chi^{2}, p=0.024\right)$ and slightly fewer number in macular synapses $\left(\chi^{2}, p=0.039\right)$. Regarding SS, the number of these synapses was not sufficient to perform a robust statistical analysis.

Moreover, we determined whether the shape of the synapses was associated with differences in their size. The area, perimeter and curvature of the SAS from each of the AS and SS were examined. In the case of the AS, the mean SAS area, perimeter and curvature of macular synapses were, as occurred in control cases, significantly smaller than in perforated, horseshoe-shaped and frag- mented synapses (KW, $p<0.0001$; Table 5; Fig. 8). Although we observed the same tendency in the case of SS (smaller macular synapses than perforated and horseshoe-shaped synapses), the number of these synapses was not sufficient to perform a robust statistical analysis. SAS features of AS such as the area, perimeter and the curvature were compared between the two groups, with no significant differences observed between control cases and AD patients (MW, $p>0.05$ ). Likewise, frequency distribution analysis did not reveal significant differences (KS, $p>0.01$ ).

\section{Discussion}

This study provides the following findings: first, both in control cases and AD patients, AS had a significant preference for spine heads, while the preference of SS was for dendritic shafts. However, in AD patients we observed a lower percentage of synapses targeting spine heads. Second, regarding the shape of synapses, in control and AD samples, the vast majority of synapses had a macular shape $(83.8 \%$ for AS and $83.5 \%$ for SS control; $81.4 \%$ for AS and $92.5 \%$ for SS AD). Third, in AD patients, we 
Table 6. Summary of the data from the studies of the pattern of synaptic distribution

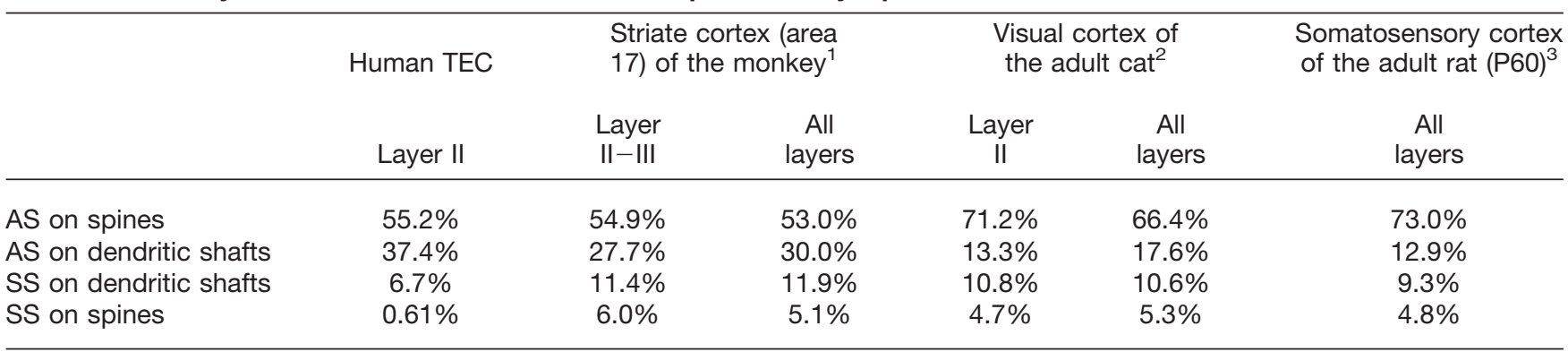

Data are given as percentages. Data were taken from: ${ }^{1}$ Beaulieu et al., 1992; ${ }^{2}$ Beaulieu and Colonnier (1985); ${ }^{3}$ Micheva and Beaulieu (1996).

observed a higher percentage of fragmented AS than in control cases.

\section{Distribution of postsynaptic targets \\ Synaptic targets in control cases}

The analysis of the preferred postsynaptic target revealed that the vast majority of AS were established on spines, whereas, in the case of SS, the vast majority were on dendritic shafts. If we take into account the synaptic type (AS or SS) and its postsynaptic target, we found that in control cases $54.7 \%$ of synapses were AS targeting spine heads, $37.4 \%$ were AS on dendritic shafts, $6.8 \%$ were SS located on dendritic shafts, and $0.5 \%$ were SS on spine heads. Very few synapses targeted spine necks (0.5\% of AS and $0.1 \%$ of SS).

Since there are no similar studies performed in the human cerebral cortex, we compared our results with EM studies performed in the neuropil of other species and cortical regions (Table 6; Beaulieu and Colonnier, 1985; Beaulieu et al., 1992; Micheva and Beaulieu, 1996). These studies include data from the monkey striate cortex, the cat visual cortex, and the rat barrel cortex. As summarized in Table 6, there is a general pattern in all cortical areas and species: AS located on spines predominate, followed by AS located on dendritic shafts, SS located on dendritic shafts, and, finally, SS located on spines. Taking into account the considerable differences in the functional and structural features between the different cortical areas and species (DeFelipe, 2011), the similarity of this general pattern of synaptic distribution is remarkable. Nevertheless, there are important differences in the percentage for each category, which could be attributed to species specialization of the different cortical areas examined. For example, Layer II of the human TEC had the lowest percentage of AS on spines, although this percentage was similar to that found in layer $2 / 3$ of the monkey striate cortex. However, the proportions of AS on shafts and SS on spines were largest and lowest, respectively, in the human TEC (Table 6). Nevertheless, we cannot rule out the possibility that the differences in the percentages observed in the present study and the above mentioned publications in experimental animals could also be explained, at least in part, by the different methodological approaches used to identify the postsynaptic targets; we used the gold standard method, namely full reconstructions of the synapses, rather than the partial reconstructions conducted in other publications.

\section{Synaptic targets in $A D$}

In the AD samples, the study of the preferred postsynaptic target showed that, as observed with control cases, the majority of AS were established on spines (with 50.2\% targeting spine heads and $0.7 \%$ targeting spine necks). The remaining AS were established on dendritic shafts (28.0\% of AS on aspiny dendritic shafts and $21.1 \%$ of AS on spiny shafts). However, the majority of SS target dendritic shafts $(49.0 \%$ on spiny dendritic shafts and $41.2 \%$ on aspiny shafts), and a small percentage of SS were established on spine heads (8.8\%) and spine necks (1.0\%).

Comparison of the postsynaptic targets in $A D$ patients and control cases revealed a significant reduction in the number of synapses targeting spine heads in AD patients. This reduction is probably related to the changes in number and morphology of spines that occur in AD. For example, in the vicinity of amyloid-plaques in the cerebral cortex of mouse models of $A D$, as well as in tissue from AD patients, spines are loss or undergo a variety of morphological changes (Spires-Jones et al., 2007; Knafo et al., 2009; Tackenberg et al., 2009; Merino-Serrais et al., 2011; Pozueta et al., 2013; Llorens-Martín et al., 2014; Zou et al., 2015). Furthermore, some studies have observed loss and morphological changes of spines in tau transgenic mice and AD patients, related to the presence of pretangles or neurofibrillary tangles in pyramidal neurons (Tackenberg et al., 2009; Merino-Serrais et al., 2013; Pozueta et al., 2013). Thus, both $A \beta$-plaques in the neuropil and the intracellular neurofibrillary tangles within pyramidal cells induce alterations in spines. Since the majority of the synapses a pyramidal cell receives are on spines and they represent the vast majority of AS synapses (DeFelipe and Fariñas, 1992), the loss of spines, and, therefore, the loss of synapses, has been proposed as the structural basis of pathogenesis in $A D$ and in other neurodegenerative diseases, such as Huntington's disease, and amyotrophic lateral sclerosis-associated dementia (Herms and Dorostkar, 2016).

Despite the fact that we found a significantly lower number of synapses targeting spine heads in AD patients, it is important to note that there was a high interindividual variability (Extended Data Table 2-1). Two AD patients (IF6, VK11), who had the lowest Braak/CERAD stage (IIIIV/A), showed values of synapses targeting spine heads similar to control cases. By contrast, one AD patient (VK22) classified with the highest Braak/CERAD stage 
(V/C) presented the lowest number of synapses targeting spine heads. Therefore, the number of synapses targeting spine heads might be modified by differences in the disease progression. By contrast, one AD patient (IF1), classified as Braak/CERAD stage IV/B, showed values of synapses targeting spine heads similar to control cases. Since this patient apparently did not display cognitive impairment, it is possible that this particular case may represent a predementia stage of AD with no impairment of spines. This variability could not be explained by technical effects, since postmortem delays were all similar and we used the same methodological procedures. However, others factors such as gender or aging could explain the variability among cases, since these factors may influence the number of synapses (Alonso-Nanclares et al., 2008; Peters and Kemper, 2012).

\section{The shape and size of the synaptic junctions: controls versus $A D$}

It is not only the number of spines that is essential in terms of maintenance of synaptic connectivity and plasticity; spine morphology is also critical from a functional point of view (Yuste, 2010; Herms and Dorostkar, 2016). The spine head volume has been related to the area of the PSD, which has in turn been related to the number of postsynaptic receptors (Nusser et al., 1998) and the probability of neurotransmitter release (Arellano et al., 2007; Montes et al., 2015). Regarding the molecular composition of the PSD, the larger the synapse, the higher the actual number of AMPA receptors, whereas a higher concentration of NMDA receptors has been found in smaller synapses (Kharazia and Weinberg, 1999). In the present study, no changes in any of the PSD size parameters (SAS area and perimeter) were found in AD samples. However, the protein composition of human synapses is highly complex (Grant, 2012) and we cannot rule out changes in the composition and number of postsynaptic receptors and other elements of the postsynaptic signaling complexes in Layer II of the TEC in AD patients. Further studies of the human synapse proteome in the TEC would be necessary to better understand the synaptic changes found in this cortical region.

In both control and AD cases, synaptic junctions were categorized into four main types depending on their shape: macular, perforated, horseshoe-shaped and fragmented synapses.

\section{Control}

In general, the vast majority of both AS and SS had a macular shape; followed far behind, the second most common type was perforated synapses in the case of AS, or horseshoe-shaped synapses in the case of SS. Fragmented synapses were found in low numbers and all of them were AS. Regarding the average size of synapses, macular synapses were smaller than perforated, horseshoe-shaped and fragmented synapses. Unfortunately, since there are no studies about the 3D synaptic morphology in the human neocortex, our results cannot be compared with previous studies performed in the TEC or in any other human cortical region. These results are similar to previous studies on synaptic shape and size performed in the juvenile rat somatosensory cortex (Santuy et al., 2018a).

Although we do not know how morphological synaptic changes affect synaptic function, some studies have related them to an increase in the synaptic transmission efficiency, because the remodeling process involves the insertion of new receptors in the postsynaptic membrane (Lüscher et al., 2000). Moreover, in response to synaptic activity, receptors can be incorporated into the PSD either by endosomal pathways or by lateral diffusion from the extrasynaptic membrane zone (Kneussel and Hausrat, 2016). Under normal conditions, the macular synapses had the capacity to become larger by progressively adopting a more tortuous perimeter with perforations and indentations (Geinisman et al., 1987, 1991, 1992a,b). So, synapses may become larger and more complex by a remodeling process involving the incorporation of receptors into the postsynaptic membrane. Accordingly, some studies have reported higher immunoreactivity for glutamate receptors (AMPA and NMDA) in perforated synapses than in non-perforated ones (Ganeshina et al., $2004 a, b)$. Models to study how variations in size of synaptic junctions are related to characteristics such as release probability of neurotransmitter and density of postsynaptic AMPA receptors suggest that large synapses with more number of postsynaptic receptors would produce stronger and more homogeneous responses, while small synapses with fewer receptors would produce weaker and much more variable responses (Montes et al., 2015).

Furthermore, it has been postulated that fragmented synapses are specialized synapses which would lead to a greater synaptic response than in the case of synapses that only have a single PSD (Geinisman et al., 1987; Ganeshina et al., 2004a). Several studies have found an increase in the number of fragmented synapses resulting from the turnover of original synapses in the dental gyrus and CA1 of the rat hippocampus after LTP or kindling stimulation (Geinisman et al., 1991, 1992a,b, 1993; Toni et al., 2001). In this process, a continuous disk-shaped PSD synapse (macular) enlarges with the formation of one or more holes in its PSD, becoming a horseshoe shape before finally separating into different PSDs with no connections between them (Geinisman et al., 1987). Thus, fragmented synapses could be structural intermediates in various forms of synaptic dynamics and their increase in their number could be responsible for the enhancement of synaptic efficacy that is typical of LTP and kindling. Finally, if perforated, horseshoe-shaped and fragmented synapses represent different dynamic functional stages, and the percentage of these synapses is relatively low, it follows that dynamic synaptic changes must be of relatively little importance.

However, we should keep in mind that, in the TEC, there are billions of synapses $\left(510 \times 10^{6}\right.$ synapses per $\mathrm{mm}^{3}$; Domínguez-Álvaro et al., 2018). Thus, there are millions of synapses with these different shapes, which could in fact be interpreted as a relatively high rate of synaptic dynamism. 
$A D$

In AD cases, the vast majority of both AS and SS were macular, followed by perforated, horseshoe-shaped and fragmented synapses. In the case of SS, the percentages of perforated and horseshoe-shaped synapses were lower than for AS, and fragmented synapses were not found.

When we compared the proportion of the different synaptic shapes between control cases and AD patients, we found that AS fragmented synapses were more frequent in $A D$ patients than in control cases. This difference was not found in macular, perforated or horseshoe-shaped synapses, although a slightly lower proportion of macular synapses and a slightly higher proportion of horseshoe synapses were found in AD patients.

In our AD samples, we also determined whether the shape of the synapses was related to the synaptic size (area, perimeter and curvature of the SAS). We observed that synapses in $A D$ samples had similar morphological features to those observed in control cases. In the case of the AS, the area, perimeter and curvature of macular synapses were significantly smaller than in perforated, horseshoe-shaped, and fragmented synapses. Moreover, regarding these synaptic features, there were no significant differences between control and AD patients, as previously reported in other cortical regions using conventional transmission EM (Scheff and Price, 2006; Scheff et al., 1993).

Since an increase in the number of fragmented synapses has been related to potentiation of the synaptic efficacy (Geinisman et al., 1991, 1992a,b, 1993; Toni et al., 2001), the increased number of this type of synapse found in $A D$ patients could be due to the activation of compensatory mechanisms in response to the synaptic loss that occurs in this cortical region (Domínguez-Álvaro et al., 2018). Accordingly, a higher number of perforated synapses have been reported in several diseases and under certain experimental conditions, such as, e.g., after striatal dopamine depletion in the striatum of the rat (Anaya-Martínez et al., 2014). Recently, enhancement of physiologic synaptic activity during early stages of $A D$ has been suggested as a compensatory response (Tampellini, 2015). Since the potentiation of synaptic activity may promote an increase in the proportion of fragmented synapses, we could hypothesize that the higher proportion of fragmented synapses found in $A D$ patients could be a compensatory mechanism during the progression of this disease, which would end in the generation of more fragmented synapses. However, it could be possible that this kind of mechanism fails and synaptic activity would fall off. Moreover, as fragmented synapses have more than one independent release site their formation could involve an increase in glutamate release, which may promote excitotoxicity and neuronal death (Anaya-Martínez et al., 2014).

Finally, although we analyzed only five control cases and five AD patients, it is important to keep in mind that, thanks to FIB/SEM technology, it was possible to obtain the first largest collection of $3 \mathrm{D}$ reconstructed synapses of the human brain, with thousands of synapses examined. This al- lowed us to accurately determine their morphology and postsynaptic targets, constituting firm support for the evidence provided by the data presented. Nevertheless, further verification involving the examination of more cases with similar ages would be necessary to better understand the possible differences in the synaptic organization between controls and $A D$. As a final point, it is well established that there are differences in the microstructure of the cerebral cortex depending on the cortical area and layer (DeFelipe, 2011). Therefore, the data obtained in the present study probably cannot be extrapolated to other cortical regions. In other words, the synaptic organization must be examined separately in each particular region and for different ages and genders. This will make it possible to determine the similarities and differences in the synaptic organization between different cortical regions of the human brain.

\section{Concluding remarks}

In summary, this study provides evidence of a reduction in the number of synapses targeting spine heads in $A D$ patients, in line with previous studies. The loss of spines, and, therefore, the loss of synapses, has been proposed as the structural basis of pathogenesis in AD. Besides, in this study we observed morphological synaptic alterations in TEC in AD patients. How these morphological changes could affect the synaptic function is unknown, but these changes have been related to modifications in the synaptic transmission efficiency. Thus, the increase in the number of fragmented synapses in AD patients could be due to the activation of compensatory mechanisms in response to the synaptic loss that occurs in this cortical region during the progression of the disease. However, it could be possible that this kind of mechanism fails and synaptic activity would fall off.

\section{References}

Alonso-Nanclares L, Gonzalez-Soriano J, Rodriguez JR, DeFelipe J (2008) Gender differences in human cortical synaptic density. Proc Natl Acad Sci USA 105:14615-14619.

Alzheimer's Association (2018) Alzheimer's disease facts and figures. Alzheimers Dement 14:367-429.

Anaya-Martínez V, Gutierrez-Valdez AL, Ordoñez-Librado JL, Montiel-Flores E, Sánchez-Betancourt J, Sánchez Vázquez del Mercado C, Reynoso-Erazo L, Tron-Alvarez R, Avila-Costa MR (2014) The presence of perforated synapses in the striatum after dopamine depletion, is this a sign of maladaptive brain plasticity? Microscopy (Oxf) 63:427-435.

Arellano JI, Benavides-Piccione R, DeFelipe J, Yuste R (2007) Ultrastructure of dendritic spines: correlation between synaptic and spine morphologies. Front Neurosci 1:131-143.

Arendt T (2009) Synaptic degeneration in Alzheimer's disease. Acta Neuropathol 118:167-179.

Beaulieu C, Colonnier M (1985) A laminar analysis of the number of round-asymmetrical and flat- symmetrical synapses on spines, dendritic trunks, and cell bodies in area 17 of the cat. J Comp Neurol 231:180-189.

Beaulieu C, Kisvarday Z, Somogyi P, Cynader M, Cowey A (1992) Quantitative distribution of GABA-immunopositive and-immunonegative neurons and synapses in the monkey striate cortex (area 17). Cereb Cortex 2:295-309.

Bewick V, Cheek L, Ball J (2004) Statistics review 8: qualitative data-tests of association. Crit Care 8:46-53.

Blazquez-Llorca L, Merchán-Pérez Á, Rodríguez JR, Gascón J, DeFelipe J (2013) FIB/SEM technology and Alzheimer's disease: 
three-dimensional analysis of human cortical synapses. J Alzheimers Dis 34:995-1013.

Braak H, Braak E (1985) On areas of transition between entorhinal allocortex and temporal isocortex in the human brain. Normal morphology and lamina-specific pathology in Alzheimer's disease. Acta Neuropathol 68:325-332.

Braak H, Braak E (1991) Neuropathological stageing of Alzheimerrelated changes. Acta Neuropathol 82:239-259.

Braak H, Braak E, Yilmazer D, Bohl J, Braak H, Braak E (1996) Topical review: functional anatomy of human hippocampal formation and related structures. J Child Neurol 11:265-275.

Coleman P, Federoff H, Kurlan R (2004) A focus on the synapse for neuroprotection in Alzheimer disease and other dementias. Neurology 63:1155-1162.

Colonnier M (1968) Synaptic patterns on different cell types in the different laminae of the cat visual vortex. An electron microscope study. Brain Res 9:268-287.

DeFelipe J (2011) The evolution of the brain, the human nature of cortical circuits and intellectual creativity. Front Neuroanat 5:29.

DeFelipe $J$ (2015) The dendritic spine story: an intriguing process of discovery. Front Neuroanat 9:14.

DeFelipe J, Fariñas I (1992) The pyramidal neuron of the cerebral cortex: morphological and chemical characteristics of the synaptic inputs. Prog Neurobiol 39:563-607.

DeFelipe J, Fairén A (1993) A simple and reliable method for correlative light and electron microscopic studies. J Histochem Cytochem 41:769-772.

Dickson DW, Crystal HA, Bevona C, Honer W, Vincent I, Davies P (1995) Correlations of synaptic and pathological markers with cognition of the elderly. Neurobiol Aging 16:285-304.

Domínguez-Álvaro M, Montero-Crespo M, Blazquez-Llorca L, Insausti R, Defelipe J (2018) Three-dimensional analysis of synapses in the transentorhinal cortex of Alzheimer's disease patients. Acta Neuropathol Commun 6:20.

Dorostkar MM, Zou C, Blazquez-Llorca L, Herms J (2015) Analyzing dendritic spine pathology in Alzheimer's disease: problems and opportunities. Acta Neuropathol 130:1-19.

Fauth M, Tetzlaff C (2016) Opposing effects of neuronal activity on structural plasticity. Front Neuroanat 10:75.

Geinisman Y, Morrell F, de Toledo-Morrell L (1987) Axospinous synapses with segmented postsynaptic densities: a morphologically distinct synaptic subtype contributing to the number of profiles of 'perforated' synapses visualized in random sections. Brain Res 423:179-188.

Geinisman Y, DeToledo-Morrell L, Morrell F (1991) Induction of long-term potentiation is associated with an increase in the number of axospinous synapses with segmented postsynaptic densities. Brain Res 566:77-88.

Geinisman Y, de Toledo-Morrell L, Morrell F, Persina IS, Rossi M (1992a) Structural synaptic plasticity associated with the induction of long-term potentiation is preserved in the dentate gyrus of aged rats. Hippocampus 2:445-456.

Geinisman Y, Morrell F, DeToledo-Morrell L (1992b) Increase in the number of axospinous synapses with segmented postsynaptic densities following hippocampal kindling. Brain Res 569:341-347.

Geinisman Y, DeToledo-Morrell L, Morrell F, Heller RE, Rossi M, Parshall RF (1993) Structural synaptic correlate of long-term potentiation: formation of axospinous synapses with multiple, completely partitioned transmission zones. Hippocampus 3:435-446.

Ganeshina O, Berry RW, Petralia RS, Nicholson DA, Geinisman Y (2004a) Synapses with a segmented, completely partitioned postsynaptic density express more AMPA receptors than other axospinous synaptic junctions. Neurosci 125:615-623.

Ganeshina O, Berry RW, Petralia RS, Nicholson DA, Geinisman Y (2004b) Differences in the expression of AMPA and NMDA receptors between axospinous perforated and nonperforated synapses are related to the configuration and size of postsynaptic densities. J Comp Neurol 468:86-95.

Grant SG (2012) Synaptopathies: diseases of the synaptome. Curr Opin Neurobiol 22:522-529.
Gray EG (1959) Axo-somatic and axo-dendritic synapses of the cerebral cortex: an electron microscope study. J Anat 4:420-433.

Henstridge CM, Pickett E, Spires-Jones TL (2016) Synaptic pathology: a shared mechanism in neurological disease. Ageing Res Rev 28:72-84.

Herms J, Dorostkar MM (2016) Dendritic spine pathology in neurodegenerative diseases. Annu Rev Pathol 11:221-250.

Insausti R, Muñoz-López M, Insausti AM, Artacho-Pérula E (2017) The human periallocortex: layer pattern in presubiculum, parasubiculum and entorhinal cortex. Front Neuroanat 11:84.

Kharazia VN, Weinberg RJ (1999) Immunogold localization of AMPA and NMDA receptors in somatic sensory cortex of albino rat. $J$ Comp Neurol 412:292-302.

Knafo S, Alonso-Nanclares L, Gonzalez-Soriano J, Merino-Serrais P, Fernaud-Espinosa I, Ferrer I, DeFelipe J (2009) Widespread changes in dendritic spines in a model of Alzheimer's disease. Cereb Cortex 19:586-592.

Kneussel M, Hausrat TJ (2016) Postsynaptic neurotransmitter receptor reserve pools for synaptic potentiation. Trends Neurosci 39: 170-182.

Llorens-Martín M, Blazquez-Llorca L, Benavides-Piccione R, Rabano A, Hernandez F, Avila J, DeFelipe J (2014) Selective alterations of neurons and circuits related to early memory loss in Alzheimer's disease. Front Neuroanat 8:38.

Lüscher C, Nicoll RA, Malenka RC, Muller D (2000) Synaptic plasticity and dynamic modulation of the postsynaptic. Nat Neurosci 3:545-550.

Masliah E, Mallory M, Alford M, DeTeresa R, Hansen LA, McKeel DW Jr, Morris JC (2001) Altered expression of synaptic proteins occurs early during progression of Alzheimer's disease. Neurology 56: 127-129.

Merchán-Pérez A, Rodriguez JR, Alonso-Nanclares L, Schertel A, DeFelipe J (2009) Counting synapses using FIB/SEM microscopy: a true revolution for ultrastructural volume reconstruction. Front Neuroanat 3:18.

Merino-Serrais P, Knafo S, Alonso-Nanclares L, Fernaud-Espinosa I, DeFelipe J (2011) Layer-Specific alterations to CA1 dendritic spines in a mouse model of Alzheimer's disease. Hippocampus 21:1037-1044.

Merino-Serrais P, Benavides-Piccione R, Blazquez-Llorca L, Kastanauskaite A, Rábano A, Avila J, DeFelipe J (2013) The influence of phospho- $\tau$ on dendritic spines of cortical pyramidal neurons in patients with Alzheimer's disease. Brain 136:1913-1928.

Micheva KD, Beaulieu C (1996) Quantitative aspects of synaptogenesis in the rat barrel field cortex with special reference to GABA circuitry. J Comp Neurol 373:340-354.

Mirra SS, Heyman A, McKeel D, Sumi SM, Crain BJ, Brownlee LM, Vogel FS, Hughes JP, van Belle G, Berg L (1991) The consortium to establish a registry for $A D$ (CERAD). Part II. Standardization of the neuropathologic assessment of Alzheimer's disease. Neurology 41:479-486.

Montes J, Peña JM, DeFelipe J, Herreras O, Merchan-Perez A (2015) The influence of synaptic size on AMPA receptor activation: a Monte Carlo model. PLoS One 10:e0130924.

Morales J, Alonso-Nanclares L, Rodríguez JR, DeFelipe J, Rodríguez Á, Merchán-Pérez Á (2011) Espina: a tool for the automated segmentation and counting of synapses in large stacks of electron microscopy images. Front Neuroanat 18:18.

Morales J, Rodríguez A, Rodríguez JR, DeFelipe J, Merchan-Pérez A (2013) Characterization and extraction of the synaptic apposition surface for synaptic geometric analysis. Front Neuroanat 7:20.

Nusser Z, Lujan R, Laube G, Roberts JD, Molnar E, Somogyi P (1998) Cell type and pathway dependence of synaptic AMPA receptor number and variability in the hippocampus. Neuron 21:545-559.

Peters A, Palay S (1996) The morphology of synapses. J Neurocytol 25:687-700.

Peters A, Palay SL, Webster HD (1991) The fine structure of the nervous system: the neurons and supporting cells, p 528. New York, NY: Oxford University Press. 
Peters A, Kemper T (2012) A review of the structural alterations in the cerebral hemispheres of the aging rhesus monkey. Neurobiol Aging 33:2357-2372.

Pozueta J, Lefort R, Shelanski ML (2013) Synaptic changes in Alzheimer's disease and its models. Neuroscience 251:51-65.

Rajmohan R, Reddy PH (2017) Amyloid-beta and phosphorylated tau accumulations cause abnormalities at synapses of Alzheimer's disease neurons. J Alzheimers Dis 57:975-999.

Santuy A, Rodríguez J, Defelipe J, Merchán-Pérez A (2018a) Study of the size and shape of synapses in the juvenile rat somatosensory cortex with 3D electron microscopy. eNeuro 5:ENEURO.0377-17.2017.

Santuy A, Rodriguez JR, DeFelipe J, Merchán-Pérez A (2018b) Volume electron microscopy of the distribution of synapses in the neuropil of the juvenile rat somatosensory cortex. Brain Struct Funct 223:77-90.

Scheff SW, Price DA (2006) Alzheimer's disease-related alterations in synaptic density: neocortex and hippocampus. J Alzheimers Dis 9:101-115.

Scheff SW, Sparks DL, Price DA (1993) Quantitative assessment of synaptic density in the entorhinal cortex in Alzheimer's disease. Ann Neurol 34:356-361.

Selkoe DJ (2002) Alzheimer's disease is a synaptic failure. Science 298:789-791.

Sharpe D (2015) Your chi-square test is statistically significant: now what? Pract Assess Res Eval 20:2-10.

Spires-Jones TL, Hyman B (2014) The intersection of amyloid beta and tau at synapses in Alzheimer's disease. Neuron 82:756-771.

Spires-Jones TL, Meyer-Luehmann M, Osetek JD, Jones PB, Stern EA, Bacskai BJ, Hyman BT (2007) Impaired spine stability under- lies plaque-related spine loss in an Alzheimer's disease mouse model. Am J Pathol 171:1304-1311.

Sze Cl, Troncoso JC, Kawas C, Mouton P, Price DL, Martin LJ (1997) Loss of the presynaptic vesicle protein synaptophysin in hippocampus correlates with cognitive decline in Alzheimer disease. J Neuropathol Exp Neurol 56:933-944.

Tackenberg C, Ghori A, Brandt R (2009) Thin, stubby or mushroom: spine pathology in Alzheimer's disease. Curr Alzheimer Res 6:261-268.

Tampellini D (2015) Synaptic activity and Alzheimer's disease: a critical update. Front Neurosci 9:423.

Toni N, Buchs P, Nikonenko I, Povilaitite P, Parisi L, Muller D (2001) Remodeling of synaptic membranes after induction of long-term potentiation. J Neurosci 21:6245-6251.

Wegner W, Mott AC, Grant SGN, Steffens H, Willig KI (2018) In vivo STED microscopy visualizes PSD95 sub-structures and morphological changes over several hours in the mouse visual cortex. Sci Rep 8:219.

Yuste R (2010) Dendritic spines. Cambridge, MA: The MIT Press.

Zou C, Montagna E, Shi Y, Peters F, Blazquez-Llorca L, Shi S, Filser S, Dorostkar MM, Herms J (2015) Intraneuronal APP and extracellular $A \beta$ independently cause dendritic spine pathology in transgenic mouse models of Alzheimer's disease. Acta Neuropathol 129:909-920.

Zhou L, Mclnnes J, Wierda K, Holt M, Herrmann AG, Jackson RJ, Wang YC, Swerts J, Beyens J, Miskiewicz K, Vilain S, Dewachter I, Moechars D, De Strooper B, Spires-Jones TL, De Wit J, Verstreken $P$ (2017) Tau association with synaptic vesicles causes presynaptic dysfunction. Nat Commun 8:15295. 